\title{
Atmospheric Horizontal Resolution Affects Tropical Climate Variability in Coupled Models
}

\author{
A. NAvarra, S. Gualdi, AND S. Masina \\ Centro Euromediterraneo per i Cambiamenti Climatic, and Istituto Nazionale di Geofisica e Vulcanologia, Bologna, Italy \\ S. Behera, J.-J. Luo, AND S. Masson \\ Frontier Research System for Global Change, Yokohama, Japan \\ E. Guilyardi And P. Delecluse \\ IPSL/LSCE, Gif-sur-Yvette, France \\ T. YAMAGATA \\ Frontier Research System for Global Change, Yokohama, Japan
}

(Manuscript received 20 March 2006, in final form 1 May 2007)

\begin{abstract}
The effect of atmospheric horizontal resolution on tropical variability is investigated within the modified Scale Interaction Experiment (SINTEX) coupled model, SINTEX-Frontier (SINTEX-F), developed jointly at Istituto Nazionale di Geofisica e Vulcanologia (INGV), L'Institut Pierre-Simon Laplace (IPSL), and the Frontier Research System. The ocean resolution is not changed as the atmospheric model resolution is modified from spectral resolution 30 (T30) to spectral resolution 106 (T106). The horizontal resolutions of the atmospheric model T30 and T106 are investigated in terms of the coupling characteristics, frequency, and variability of the tropical ocean-atmosphere interactions. It appears that the T106 resolution is generally beneficial even if it does not eliminate all the major systematic errors of the coupled model. There is an excessive shift west of the cold tongue and ENSO variability, and high resolution also has a somewhat negative impact on the variability in the east Indian Ocean. A dominant 2-yr peak for the Niño-3 variability in the T30 model is moderated in the T106 as it shifts to a longer time scale. At high resolution, new processes come into play, such as the coupling of tropical instability waves, the resolution of coastal flows at the Pacific-Mexican coasts, and improved coastal forcing along the coast of South America. The delayed oscillator seems to be the main mechanism that generates the interannual variability in both models, but the models realize it in different ways. In the T30 model it is confined close to the equator, involving relatively fast equatorial and near-equatorial modes, and in the high-resolution model, it involves a wider latitudinal region and slower waves. It is speculated that the extent of the region that is involved in the interannual variability may be linked to the time scale of the variability itself.
\end{abstract}

\section{Introduction}

The numerical resolution of a general circulation model is a major factor that affects the numerical simulation of the atmosphere and/or the ocean. It is natural that considerable attention has been spent on the investigation on how changing the numerical resolution

Corresponding author address: A. Navarra, Istituto Nazionale di Geofisica e Vulcanologia, Via Donato Creti 12, Bologna, Italy. E-mail: navarra@bo.ingv.it will affect the quality of the simulation. Though vertical and horizontal resolutions are probably equally important, most of the studies have focused on the horizontal resolution. The number of papers devoted to the subject is very large, starting with early work at the Geophysical Fluid Dynamics Laboratory (GFDL; Manabe et al. 1970) and continuing with later studies on the impact of resolution for extended range (10 days), monthly, and seasonal scales (Tibaldi et al. 1990; Boville 1991; Boyle 1993; Williamson et al. 1995; Brankovic and Gregory 2001). These studies showed that the

DOI: 10.1175/2007JCLI1406.1

(C) 2008 American Meteorological Society 
evaluation of the effect of resolution is often difficult as the changes in the numerics affect the components of the models in a complex way: overall the change to higher resolution is beneficial, but often it is not uniform across the model parameters and processes. The major systematic errors of a model cannot be eliminated simply by increasing resolution, even if a readjustment of the parameterization is performed (Duffy et al. 2003). Higher resolution does not appear to be a magical solution to all the illnesses of the model, but rather it defines a more advanced work field for the modeler, permitting the explicit treatment of more processes.

Several papers have investigated the impact of resolution, mainly horizontal resolution, for specific processes or phenomena. Bengtsson et al. (1995) showed that simulation of tropical cyclones is more realistic at the higher horizontal resolution considered in the study (T106). Recently, Kobayashi and Sugi (2004) have shown that the number of simulated tropical cyclones tends to increase at an even higher resolution. Gualdi et al. (1997) investigated the impact of resolution on the simulation of the MJO and they found that resolution alone cannot improve the accuracy of the simulation of the oscillation. The simulations of the Asian summer monsoon have been shown to be sensitive to horizontal resolution (Sperber et al. 1994; Stephenson et al. 1998; Kobayashi and Sugi 2004), leading to positive results at increased resolution. Horizontal resolution is also crucial to accurately treat the effects of ice sheets (Wild et al. 2003) and Greenland orography (Junge et al. 2005).

The impact of atmospheric horizontal resolution at climate scales has received comparably less attention. Most investigations have been conducted with prescribed SST distribution for relatively short periods using observed SST (Roeckner et al. 1996; Duffy et al. 2003; Stratton 1999; Pope and Stratton 2002) or as timeslice experiments with SST from lower-resolution coupled models (May and Roeckner 2001; May 2003, 2001).

There is almost no documentation of the effect of atmospheric resolution in coupled models. Some aspects of it were shown in Guilyardi et al. (2004) and Gualdi et al. (2005), but a more extended study at climate time scales is lacking. We present here an analysis of the interannual climate sensitivity to atmospheric horizontal resolution by examining numerical simulations performed with a coupled model developed by the cooperation between the Istituto Nazionale di Geofisica e Vulcanologia (INGV), the L'Institut PierreSimon Laplace (IPSL) groups, and the Frontier Group at the Earth Simulator Center in Japan.

The focus of this paper is on the tropical coupled dynamics. The numerical setup is such that the atmospheric model resolution is varied, but the ocean model is maintained at the same resolution. We have performed a set of simulations with the same ocean model coupled to the atmospheric model at two different horizontal resolutions, the first truncated at spectral resolution 30 (T30) and the second truncated at spectral resolution 106 (T106). The simulations were of sufficient length to be able to establish significant statistical results $(200 \mathrm{yr})$. Some of the aspects of the T30 variability were investigated by Guilyardi et al. (2003).

The changes in the atmospheric resolution do affect the variability in the tropical Pacific, even if the ocean model has not been changed at all. The impact of the horizontal resolution changes can be noted in a general indicator of the tropical variability, such as the time spectrum of the Niño-3 SST index (Fig. 1). The top panel of Fig. 1 shows that the coupled model with a low-resolution atmosphere exhibits a marked peak of variability around 2 yr (Guilyardi et al. 2003) and comparatively small variability everywhere else. The coupled model with the high-resolution atmosphere shifts the major variability peaks toward longer time scales. The variability is overestimated with respect to the observations and there are still some remains of the misplaced peak at around $2 \mathrm{yr}$, but there is a noticeable improvement. In the following we will refer to these two experiments as the low- and high-resolution experiments, respectively.

The improved horizontal resolution impacts also the teleconnections properties of the variability (Fig. 2). The regression pattern in the observation of the Niño-3 SST index with the SST elsewhere is a wide wedge pattern protruding into the Pacific Ocean. The lowresolution model displays a regression pattern that is weaker in total amplitude and it is more confined to the equator than the observations, whereas the high resolution is showing a higher amplitude and a wider pattern in latitude. Though the main systematic errors in the teleconnection are not automatically solved by the shift to high resolution, we can see that the higherresolution coupled model yields a more realistic pattern and indicates a general beneficial trend.

Modifying the atmospheric resolution, therefore, affects the ocean behavior and ocean variables even if the ocean model is not modified in the coupling.

In the following, we will investigate the mechanisms that allow this effect to take place. We will characterize the time-mean patterns of the models and their variability, the wave propagation, and the changes in the coupling properties of the models. We will investigate how the interannual variability, the teleconnections properties, and the coupled manifold introduced by Na- 

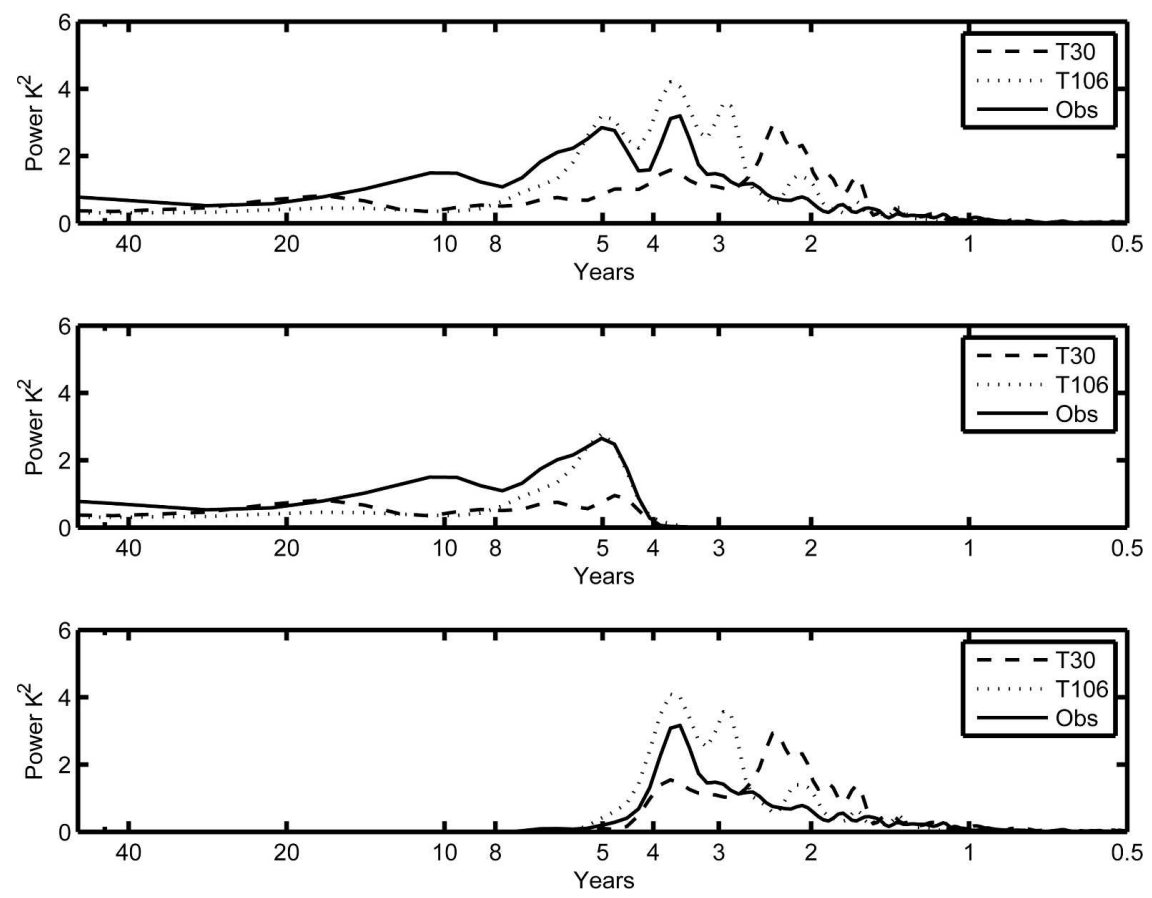

FIG. 1. (top) Power spectra of the Niño-3 index for the simulations and for observations. (middle) The spectra obtained with a low-pass Chebyshev filter with a nominal cutoff at $5 \mathrm{yr}$. (bottom) The high frequency remainder.

varra and Tribbia (2005) are sensitive to the changes in horizontal resolution.

In the following, section 2 will describe the numerical experiments and the general properties of the basic state and the variability, section 3 will describe in detail the sensitivity to resolution of the interannual variability mechanisms in the Pacific, section 4 will discuss how the resolution differences impact processes in the $\mathrm{Pa}$ cific that contribute to shaping the basic state, including the coupling of tropical instability waves (TIW), and section 5 will investigate how changes in resolution of the atmosphere modify the geographical extent and intensity of the coupling between ocean and atmosphere differences. Section 6 will summarize the discussion and then conclusions in section 7 will close the paper.

\section{Design of the numerical experiments}

The simulations were performed with the model developed for the Scale Interaction Experiment (SINTEX) project (Gualdi et al. 2003a,b; Navarra 2003; Guilyardi et al. 2003) by coupling the ECHAM4 atmospheric model and the ORCA ocean model. The model has been also implemented on the Earth Simulator computer (Luo et al. 2003). Several horizontal resolutions for the atmosphere have been coupled to the same configuration of the same ocean model. In the following we will consider only T30 and T106. No particular effort has been made to change or modify the parameterizations between the T30 and T106 version. The resolution for the ocean model has been left the same as previously used in the quoted work, that is, roughly 2 by 2 with an equatorial enhancement corresponding to an effective meridional resolution of $0.5^{\circ}$ between $10^{\circ}$ latitude and the equator. The simulations were extended for $200 \mathrm{yr}$.

The observations dataset for the surface stress have been taken from the National Centers for Environmental Prediction-National Center for Atmospheric Research (NCEP-NCAR) reanalysis (Kalnay et al. 1996; Kistler et al. 2001) on a $192 \times 94$ Gaussian grid representing a resolution of $1.8^{\circ}$ latitude and $1.875^{\circ}$ longitude. The reanalysis wind stresses have a global extent that is convenient for the analysis in this paper. For the tropical Pacific, the NCEP stresses have been evaluated with respect to other products like the Florida State University (FSU) wind by Wittenberg (2004). He found that although FSU winds are slightly closer to observations, the two products are relatively consistent at interannual scales. The Hadley Centre Sea Ice and SST (HadISST) compilation (Rayner et al. 2003) has been used for the SST, whereas other internal ocean variables, such as the vertically integrated heat content (HC), have been obtained from the ocean reanalysis 

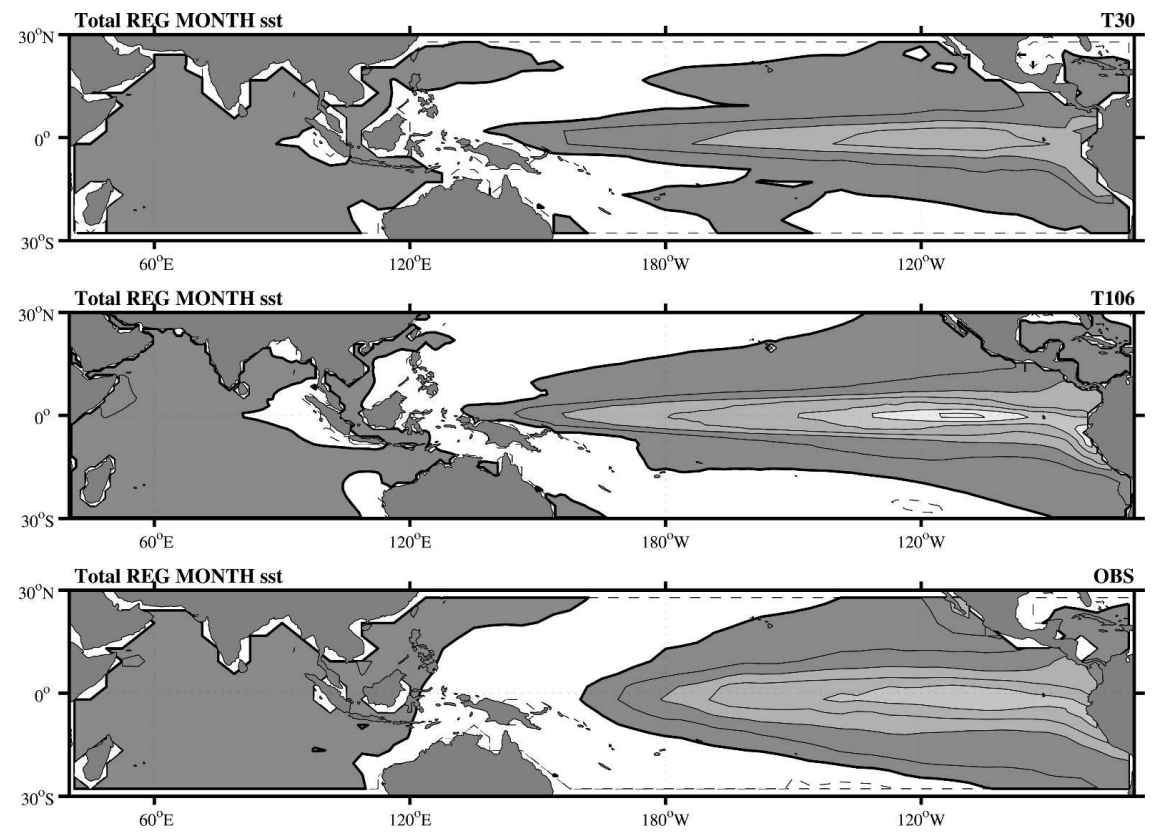

FIG. 2. Teleconnection pattern of the tropical SST expressed as a regression to the Niño-3 index. (top) The coupled model with the T30 atmosphere, (middle) the coupled model with the T106 atmosphere, and (bottom) the observations. The contour is $0.2 \mathrm{~K}$ and positive values are shaded.

performed at INGV (Masina et al. 2001) in the highresolution version, $0.5^{\circ} \times 0.5^{\circ}$ (Masina et al. 2004). The wind stresses from the coupled experiments are used on the atmospheric model Gaussian grid.

\section{a. The time-mean response}

The models show a reasonable simulation of the annual mean and seasonal SST, but the familiar signature of the double ITCZ can be easily seen. We show the summer [July-September (JAS)] response in Fig. 3. The systematic error of the double ITCZ can be seen in the band of excessive warm waters south of the equator in the central and west Pacific. The SST in the east Pacific is underestimated by the T30, with relatively cool temperatures. The T106 model (middle panel) is generally better in the geographical distribution, but the amplitude is larger than in the observations in the west Pacific and also in the Indian Ocean. The SST in the T106 coupled model, however, does show some improvement in the east Pacific and especially along the coast of South America. The temperature is markedly colder than the in the T30 model.

The surface wind stresses are shown separately for summer (JAS) and winter [January-March (JFM)] in Figs. 4 and 5. In the summer season, in the highresolution experiment, the Somali jet in the Indian Ocean has a better position and the magnitude is more similar to the observations. The cross-equatorial flow is reduced and the intensity of the wind is reduced around the equator. The winds are weaker in the southern Indian Ocean in the high-resolution experiment with respect to the low-resolution experiment and the observations. In the Pacific, the large spurious maximum centered on Hawaii is reduced and the geographical extension is better. The strong cross-equatorial flow in the eastern Pacific is substantially reduced, leading to a better orientation of the wind vectors in the area. In the southern Pacific, the high-resolution winds are weaker than the low resolution and the observation in the east.

During northern winter, the differences are less visible. It is possible to note a reduction of the winds in the western and central Pacific, south of Hawaii, and along the equator west of the date line. The winds in the Arabic Sea are also reduced. In general, with the highresolution model, the winds show a slightly better agreement with the observations but not in all locations.

It is interesting to examine with more detail the stresses along the coast of South America (Fig. 6) in the summer season. The observations here show a general northward and alongshore flow that is concentrated into a narrow band along the coast. The T30 model simulates the general flow, but the structure of the curl along the coast is very wide and it extends far from the coast. When this pattern is interpolated onto the ocean 

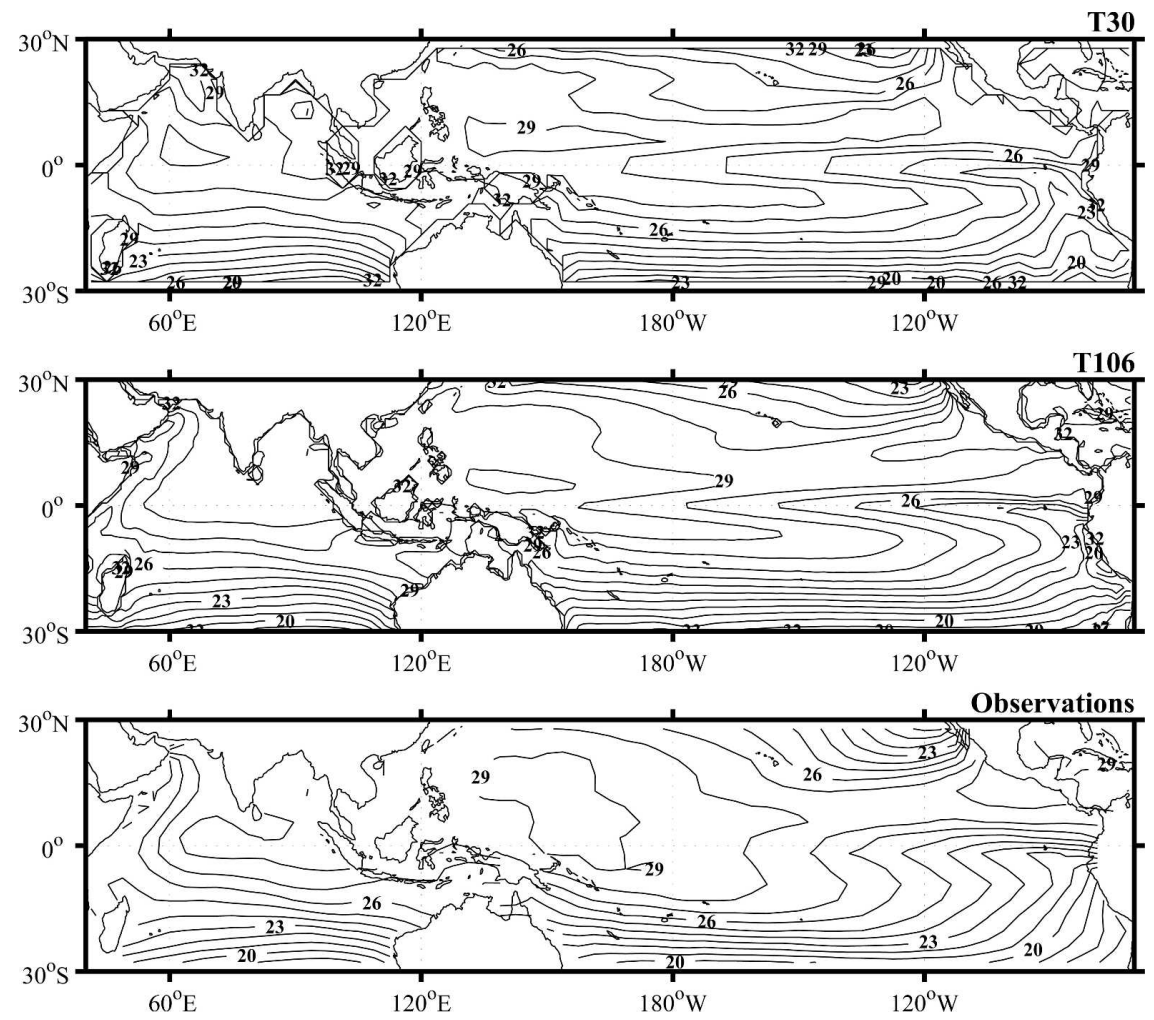

FIG. 3. Time-mean temperature fields for summer (JAS) for (top) the T30 experiment, (middle) the T106 experiment, and (bottom) the observations (HadISST). The contour interval is $1^{\circ} \mathrm{C}$.

model, the grid points of the ocean model close to the coast will experience the weak, broad curl pattern that is visible. This is in contrast with observations where the curl is more intense and concentrated. The highresolution model reproduces the intense curl along the coast better. It is reasonable to assume that this will affect the SST through upwelling and generate colder SSTs in this area, which is seen in the high-resolution experiment.

The general conclusion from the analysis of the timemean state for the field involved in the tropical coupled dynamics is that the T106 model shows a general improvement of the simulations with respect to the lowerresolution version, although it did not remove the overall characteristics of the systematic error.

\section{b. The SST standard deviation}

Figure 7 shows the standard deviation pattern of the SST for the summer in the models and in the observations. It is possible to see the expanded region of high variability in the high resolution, both in latitude and longitude and the excessive area in the Indian Ocean. In general, the standard deviation of the low-resolution model shows a weaker variability than observations. The high-resolution model generally improves, generating a more vigorous variability in the eastern and central Pacific. The T106 model has indeed a tendency to expand too much into the west Pacific and it generates a strong variability in the east Indian Ocean, shown here for the summer season (JAS) but also present in the other seasons.

\section{The teleconnections in the equatorial Pacific region}

This section will investigate the impacts of the changes in atmospheric resolution on the simulations of the main modes of interannual climate variations in the tropical areas. The focus will be on the ENSO variability and the mechanisms that have been selected in the models to produce it.

\section{a. The Niño-3 variability}

The dominant time scales of the variability in the equatorial Pacific Ocean is described in Fig. 1. The top panel shows the spectra of the Niño-3 index for the 

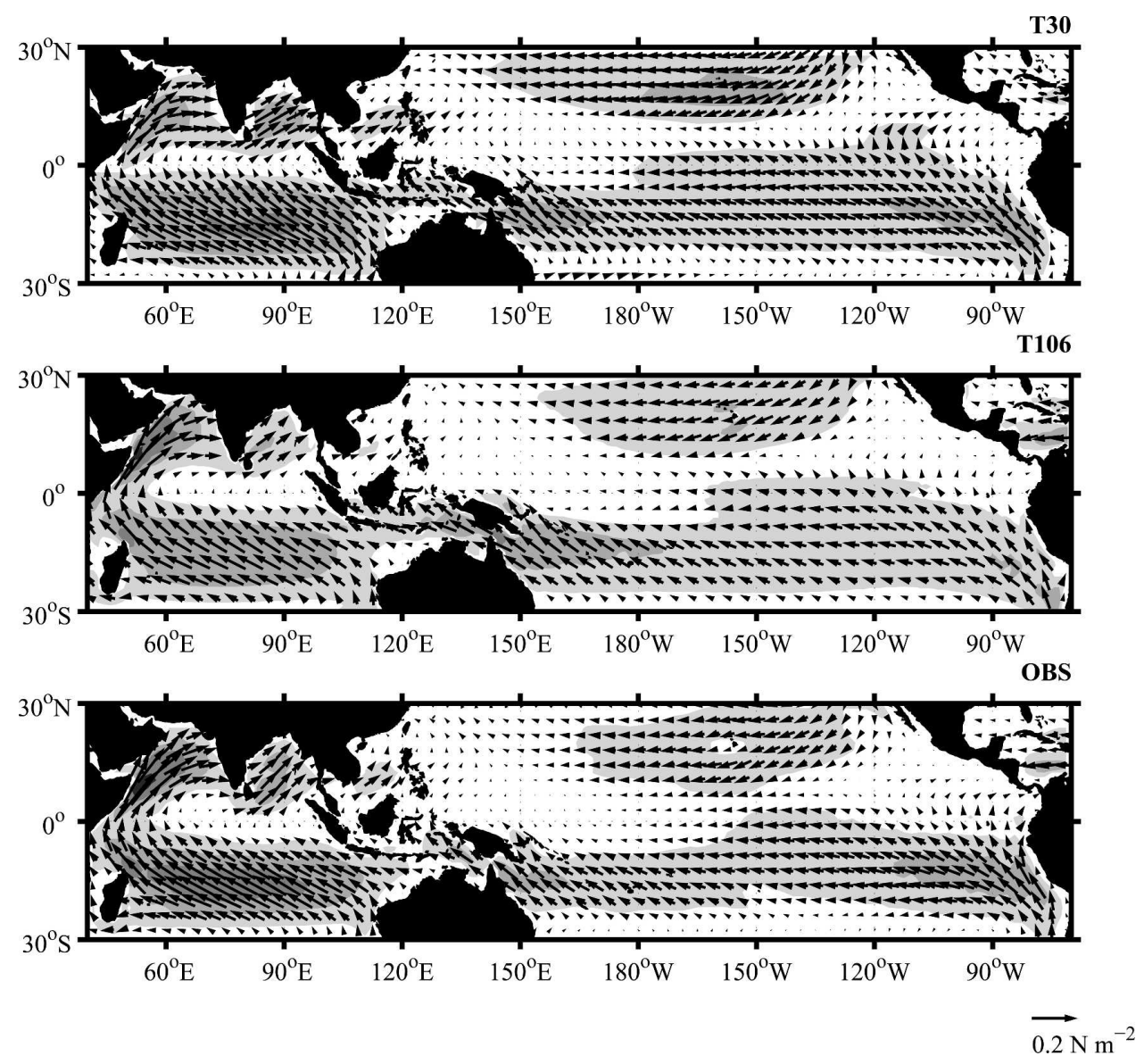

FIG. 4. Climatological surface stresses (arrows) and intensity (shades) for JAS. (top) Low-resolution model, (middle) high-resolution model subsampled for clarity, and (bottom) observations. Shading starts at $0.1 \mathrm{~N} \mathrm{~m}^{-2}$ with a contour interval of $0.05 \mathrm{~N} \mathrm{~m}^{-2}$.

numerical experiments and the observations. The spectra were obtained using a Welch window (Welch 1967) with a 30-yr overlapping window. The major spectral peaks in the picture, the 2-yr peak for the T30 and the two larger peaks for the observations and T106, are essentially robust to variations in the window formulation or extension. We are not going to focus too much on the discussion of the individual detail of the spectrum, but it is possible to conclude that the T30 has a tendency to produce variability at shorter time scales than the observations, whereas the T106 model generates variability also at longer time scales. The other panels in the figure show the same spectra after the application of a low-pass filter that will be used in the following section. The filter used is a Chebyshev filter with a cutoff at $5 \mathrm{yr}$. The improved representation of the variability in the Niño-3 area can also be seen from the autocorrelation function (Fig. 8). The autocorrelation for the T106 model shifts to longer time scales, improving with respect to the T30 model and resulting in a closer agreement to the time scale of the observations.

\section{b. Teleconnections}

The finer horizontal resolution impacts the teleconnections properties of the variability (Fig. 9, lower panels). The picture shows the regression of the monthly tropical SST to the Niño-3 index. The computations include the entire length of the simulations, and the observations are based on the HadISST dataset (Rayner et al. 2003). The regression pattern in the observation is a wide wedge pattern protruding into the Pacific Ocean. The maximum amplitude reaches $1.0 \mathrm{~K}$ at the equator in the eastern Pacific and decreases smoothly toward the zero line in the western Pacific. The low-resolution model displays a regression pattern that is weaker in total amplitude and it is more confined to the equator than the observations. The high resolution is showing a higher amplitude and a slightly wider pattern in latitude. Both models show a typical system- 

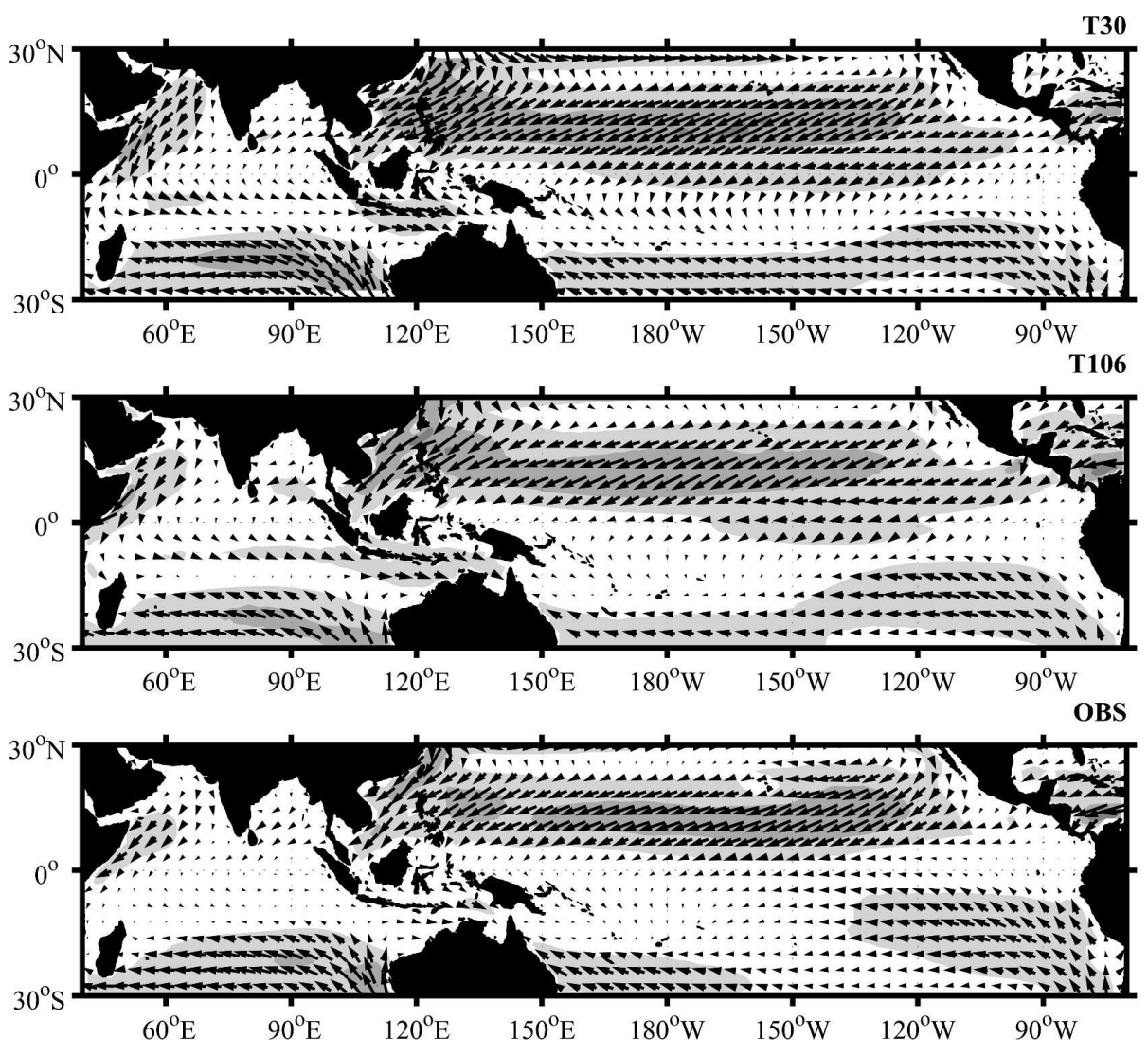

$\overrightarrow{0.2 \mathrm{~N} \mathrm{~m}^{-2}}$

FIG. 5. As in Fig. 4 but for winter (JFM).
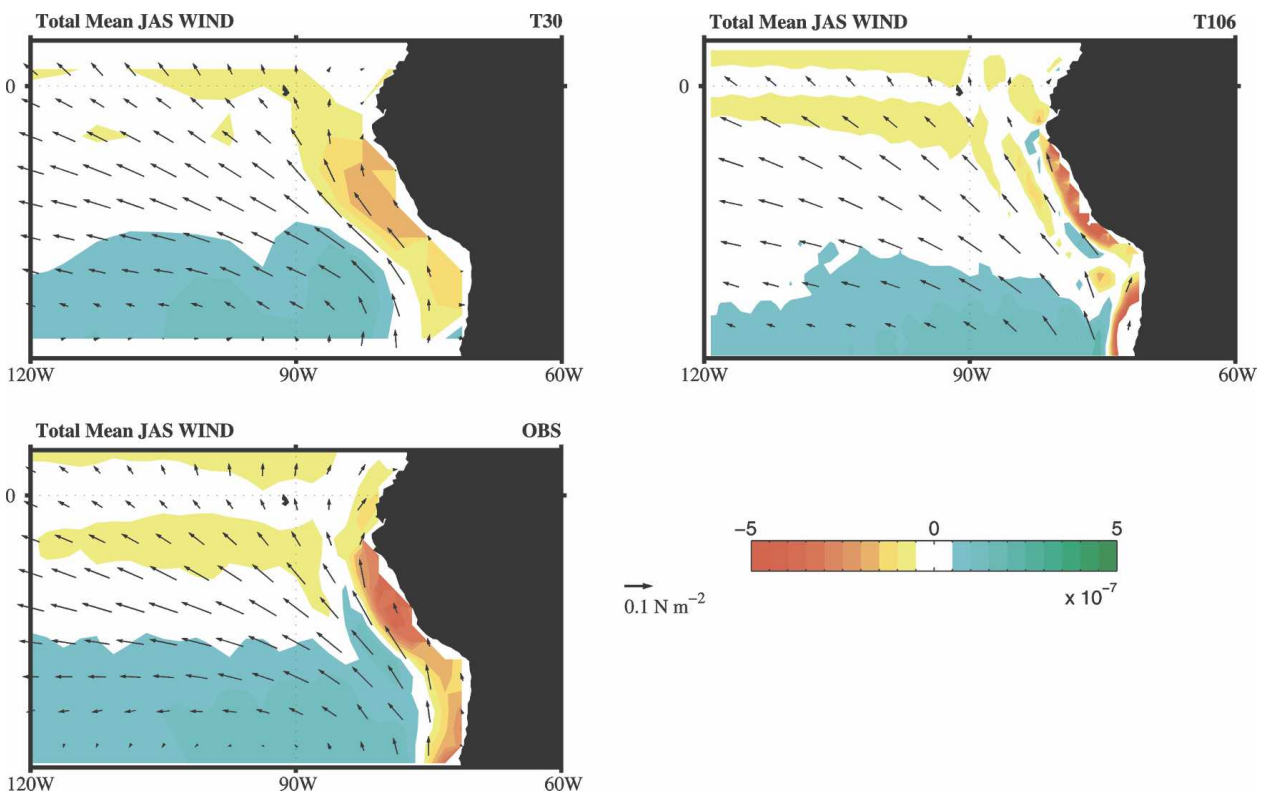

FIG. 6. Detail of the stress field (arrows) and of the curl (shades): (left) T30, (right) T106, and (bottom) observations. Positive values are red-yellow and negative values are blue; the contour interval is $0.5 \times$ $10^{-7} \mathrm{~N} \mathrm{~m}^{-3}$. 

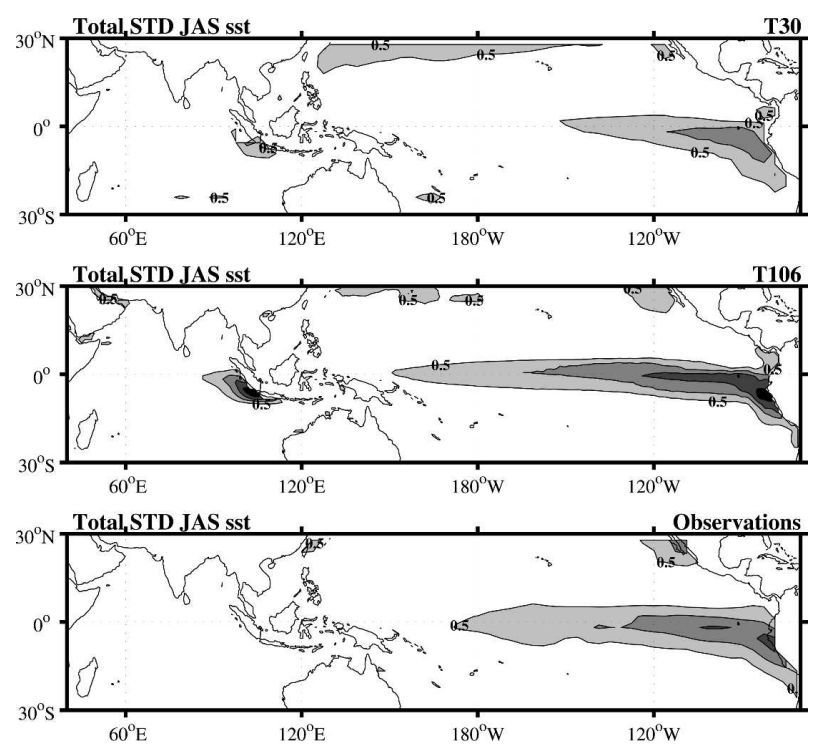

FIG. 7. Std dev of the SST for summer computed from seasonal means (JAS): (top) T30, (middle) T106, and (bottom) observations. Areas greater than $0.5 \mathrm{~K}$ are shaded. The contour interval is $0.5 \mathrm{~K}$.

atic error by invading too much of the western Pacific with positive regression. The position of the zero line is too far west in both models; however, the general shape of the zero line in the high-resolution model is less noisy than in the low-resolution model. Luo et al. (2005) have indicated that this deficiency can be improved by changing the parameterization of the wind stress.

The other panels in Fig. 9 show the same regression after the application of the low-pass filter used in Fig. 1 (upper panels) and for the remainder after the low-pass component had been subtracted (middle panels). The fast time scales are clearly recognizable in the regression pattern for both T30 and T106 models, but the slower component is markedly underestimated in the T30, and it reaches amplitude comparable with observations only in the T106 case. This model has also a better shape of the regression, indicating the typical wedge pattern into the Pacific Ocean. The greater am-

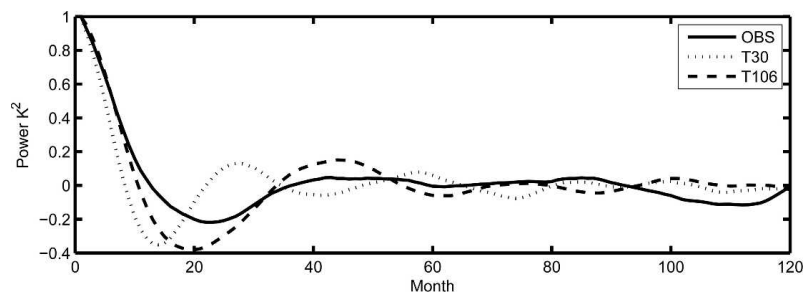

FIG. 8. Autocorrelation of the Niño-3 index for the T30 and T106 model simulations and for the observations. plitude of the low-frequency variability indicated in the spectral shape of the Niño-3 index is therefore not limited to the equatorial region, but it is part of a larger pattern that leads to greater amplitude at a slow time scale for the T106 model.

Also the regression with the zonal stress shows some improvements. Figure 10 shows the regression of the zonal wind stress to Niño-3 SST index. A bandpass filter between 1 and $5 \mathrm{yr}$ has been applied following Capotondi et al. (2006). The high-resolution model has a better agreement with the observations in magnitude in the central Pacific. The "center of mass" of the zonal stress, computed according to Capotondi et al. (2006), is located closer to the observations $\left(195^{\circ} \mathrm{E}\right.$ longitude) in the T106 $\left(194^{\circ} \mathrm{E}\right)$ than in the $\mathrm{T} 30\left(188^{\circ} \mathrm{E}\right)$. The meridional scale of the regression does not show significant change in the central Pacific, but in the east Pacific the meridional profile is more realistic in the highresolution model (Fig. 11).

The SST represents the field that is more readily affecting the atmosphere, but the ocean dynamics can be followed better by considering the upper-ocean HC, which can represent also the variability at the thermocline level. The regression of the heat content, defined here as the normalized vertical integral of temperature over the top $300 \mathrm{~m}$, to the Niño-3 index is shown in Fig. 12 in a similar way as Fig. 11. The bottom panels show how the high-resolution regression is improving over the low-resolution version, getting closer to the observations. In this case the observations are provided by the ocean reanalysis of Masina et al. (2004). The modeled HC is weaker than in the observations in the east Pacific, especially in the lowresolution case. The east-west gradient is also improved as the negative heat content anomalies in the west also get more intense.

A visible gradient appears in the Indian Ocean with visible positive/negative anomalies closer to the observations in the high-resolution case. The T106 simulation also shows more clearly the narrow band of regressions along the west coast of the North American continent. Figure 12 definitely suggests increased variability along the American coast linked to the equatorial Niño-3 variations.

There are visible changes also in the low-pass components. It is hardly visible at all in the T30 model, but it starts to be recognizable in the T106 model. Negative areas of regression appear in the west Pacific, north and south of the equator, which were present in the observations but absent in the T30 model. The amplitude increases in the east Pacific at the equator. The highpass component is also improved, especially in the central Pacific. A positive center appears in the T106 

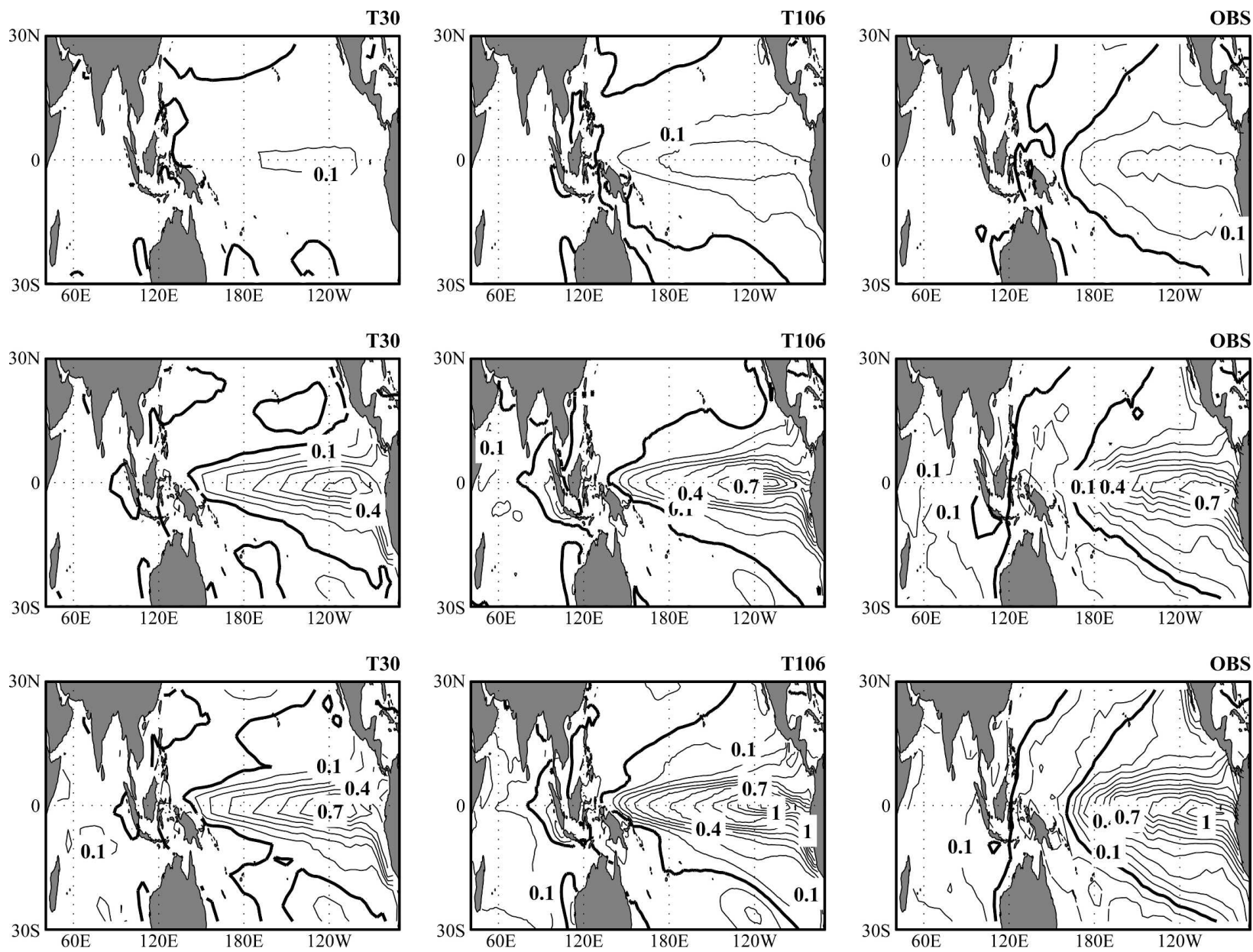

FIG. 9. Global teleconnections for the Indo-Pacific region expressed as a regression of the Niño-3 index with the SST; (right) the observations, (middle) the high-resolution T106 experiment, and (left) the low-resolution T30 experiment. The top row is the data after the application of the filter used in the spectrum in Fig. 1, and the middle row is the teleconnections for the remainder after the low-frequency portion has been removed; the total teleconnections are shown in the bottom row. The contour interval is $0.1^{\circ} \mathrm{C}$.

model, as indicated by the observations, but the T30 model has some difficulty in simulating it.

The regression of the zonal wind stress shows less remarkable changes (Fig. 10), but it is possible to note a weakening of the negative regression values to the south of the equator in the central Pacific that were not present in the observations. There is also a better representation in the high-resolution experiment of the axis of negative regression from the west South Pacific to the Indian Ocean.

\section{c. Lagged teleconnections}

The models reproduce the main mechanism of ENSO variability through the delayed oscillator mechanism (Battisti 1988; Schopf and Suarez 1990; Suarez and Schopf 1988). It is possible to follow the evolution of the ENSO phases by regressing the fields involved in the coupling on the Niño-3 index. Figure 13 shows the lagged regression to Niño-3 for the heat content. The index is leading the field. If we look at the observations (right column) we can see that after 3 months the positive heat content is shifting toward the east Pacific; the shape and speed of the propagation are consistent with equatorial Kelvin waves. But we can also see that a signal consistent with the signature of coastal Kelvin waves is racing north and south along the west coasts of North and South America. Westward off-equatorial propagation with the signature of Rossby wave packets can be seen in the west Pacific around $10^{\circ}-15^{\circ} \mathrm{N}$. At 6-month lags, the east Pacific is still warm, but the Kelvin wave has basically dissipated against the coast. Rossby waves, triggered by the coastal Kelvin waves can be seen around $10^{\circ}-15^{\circ} \mathrm{N}$, propagating slowly west. Remnants of the Rossby waves close to the Philippines 

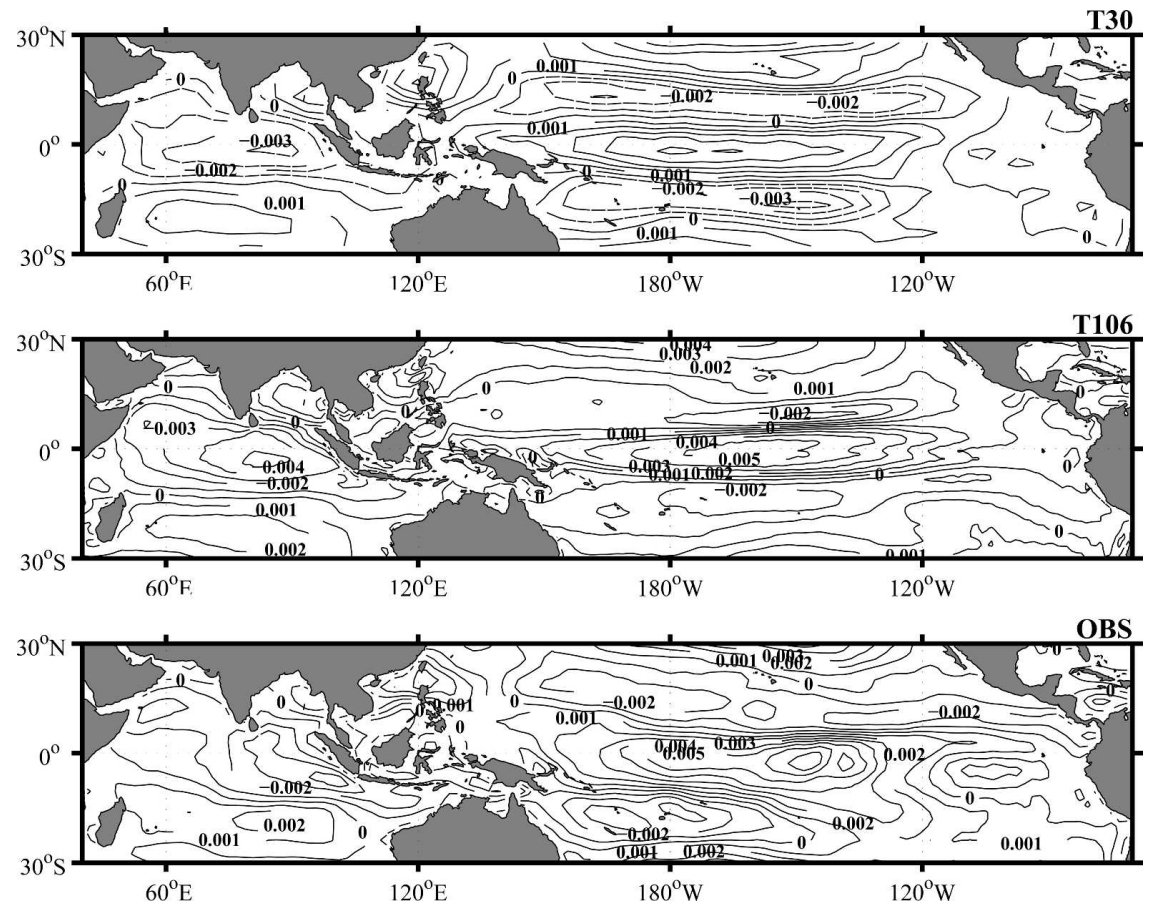

FIG. 10. Global teleconnections for the Indo-Pacific region expressed as a regression of the Niño-3 index with the zonal stress; (top) the low-resolution T30 experiment, (middle) the high-resolution T106 experiment, and (bottom) the observations. The contour interval is 0.001 $\mathrm{N} \mathrm{m}^{-2}$.

can still be seen. This is the basic mechanism of the delayed oscillator.

The better capacity of the high-resolution model to maintain the delayed oscillator can be seen in Fig. 14. As the lag period increases, we can see the phases of the

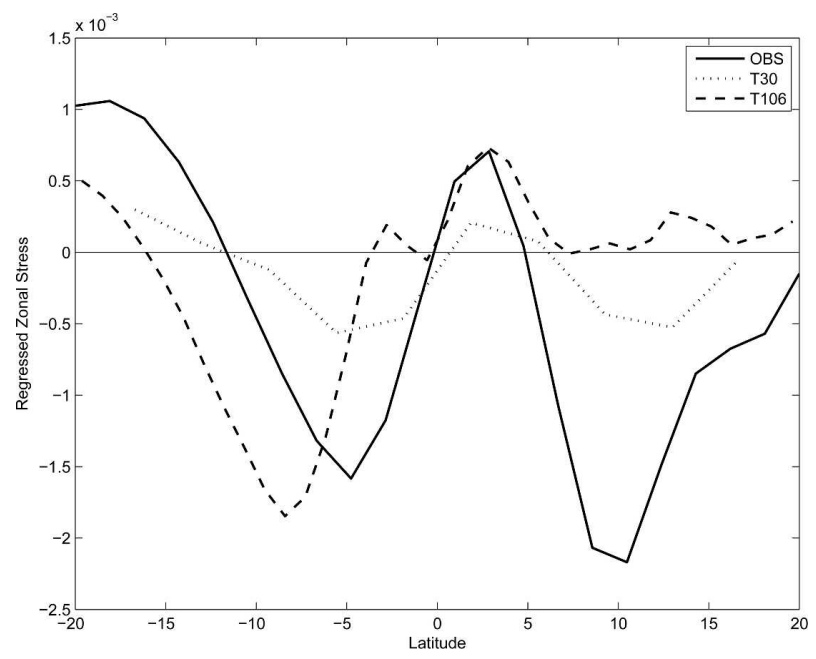

FIG. 11. Meridional profile of the Niño-3 regressed stress for the reanalysis and the T30 and T106 models, averaged in the east Pacific, between $120^{\circ}$ and $90^{\circ} \mathrm{W}$. delayed oscillator mechanism deploy one after another as cold Kelvin waves at the equator and Rossby waves off the equator take their turn in propagating across the Pacific.

The models (left and center column in Fig. 13) show the same general mechanism, but several differences can be noted. The low-resolution model shows a faster cycling through the phases of the oscillations. At 6-month lags, the east Pacific has already changed sign and it now shows cold anomalies. The coastal Kelvin waves are very weak and the west Pacific Rossby waves are as well. This situation is a signature of the dominant 2-yr cycle of the ENSO in the T30 model (see Fig. 1). The pattern is much improved with the high-resolution model. The cycle is slower and the overall dynamics is better captured, including the coastal Kelvin waves and off-equatorial Rossby waves. The amplitude is overall improved and more realistic. Significant improvements can be seen also in the Indian Ocean.

A similar regression for the zonal stress (not shown) shows that the T106 model keeps the regression with Niño-3 longer than the low-resolution model, following more closely the evolution of the observations. The zonal stress maintains contact with the SST longer in the high-resolution model than in the lower-resolution 

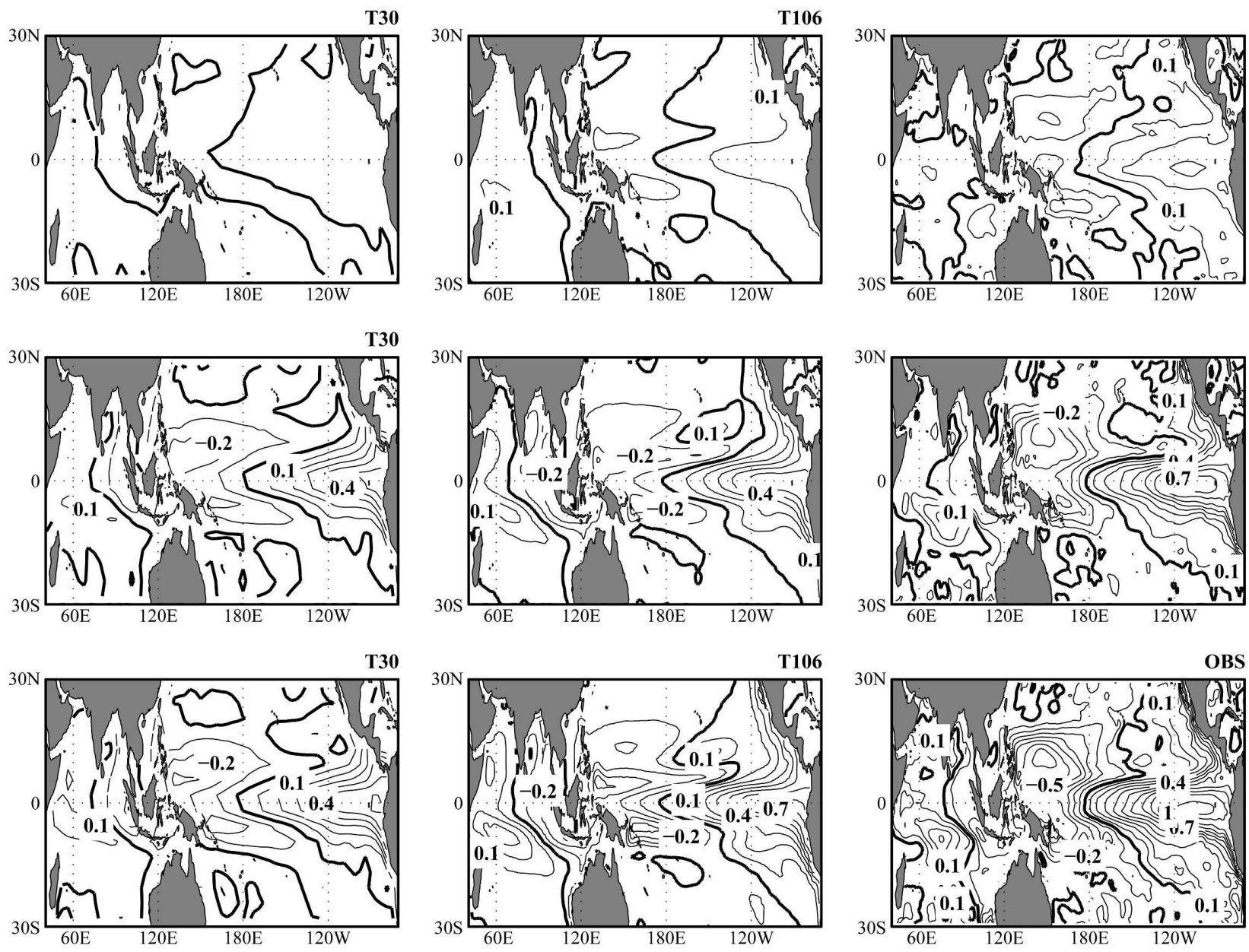

FIG. 12. As in Fig. 9 but for the ocean heat content. The contour interval is $0.1^{\circ} \mathrm{C}$.

one, consistent with Gualdi et al. (2005). The longer lag patterns show how the interaction evolves. The regression values become really small at long lags for the low-resolution model, indicating a weakening of the coupling between the ocean and the atmosphere. The low-resolution model detaches from the atmosphere rather quickly and it shows very faint traces of the wave dynamics that is necessary for the oscillations in the equatorial Pacific. The high-resolution model keeps contact longer, but still less than in reality. However, the wave dynamics initiated by the previous interaction is still active and the waves keep circulating for a longer time.

Wave propagation can also be shown using Hovmöller diagrams off the equator. Figure 15 shows the Hovmöller diagrams for a composite of positive El Niño cases. The composite has been produced by selecting cases with the Niño-3 index larger than a 1.0 standard deviation departure from the climatological mean for the month of January. The year correspond- ing to mid January is the zero year and then two years have been selected before and after. The top row shows the time-longitude evolution for the oceanic heat content averaged over the latitude band $15^{\circ}-20^{\circ} \mathrm{N}$. The other rows show the Hovmöller diagram for the latitude bands $10^{\circ}-15^{\circ} \mathrm{N}$ and $5^{\circ} \mathrm{S}-5^{\circ} \mathrm{N}$, respectively.

The equatorial plots show the typical signature of the thermocline oscillations and it is possible to note the equatorial Kelvin waves toward the east. The T30 model shows clearly the rapid 2-yr oscillation typical of this model, whereas the reanalysis shows a longer period with a slower return from the El Niño phase.

The off-equatorial dynamics is shown in the upper rows. The apparent speed of propagation of the disturbances is consistent with Rossby waves that are clearly generated in the east and then propagate toward the west. In the latitude band $10^{\circ}-15^{\circ} \mathrm{N}$ some slow activity, presumably produced by Rossby waves, can be noticed in the central and east Pacific and both models capture the wave generation and propagation. The propagation 

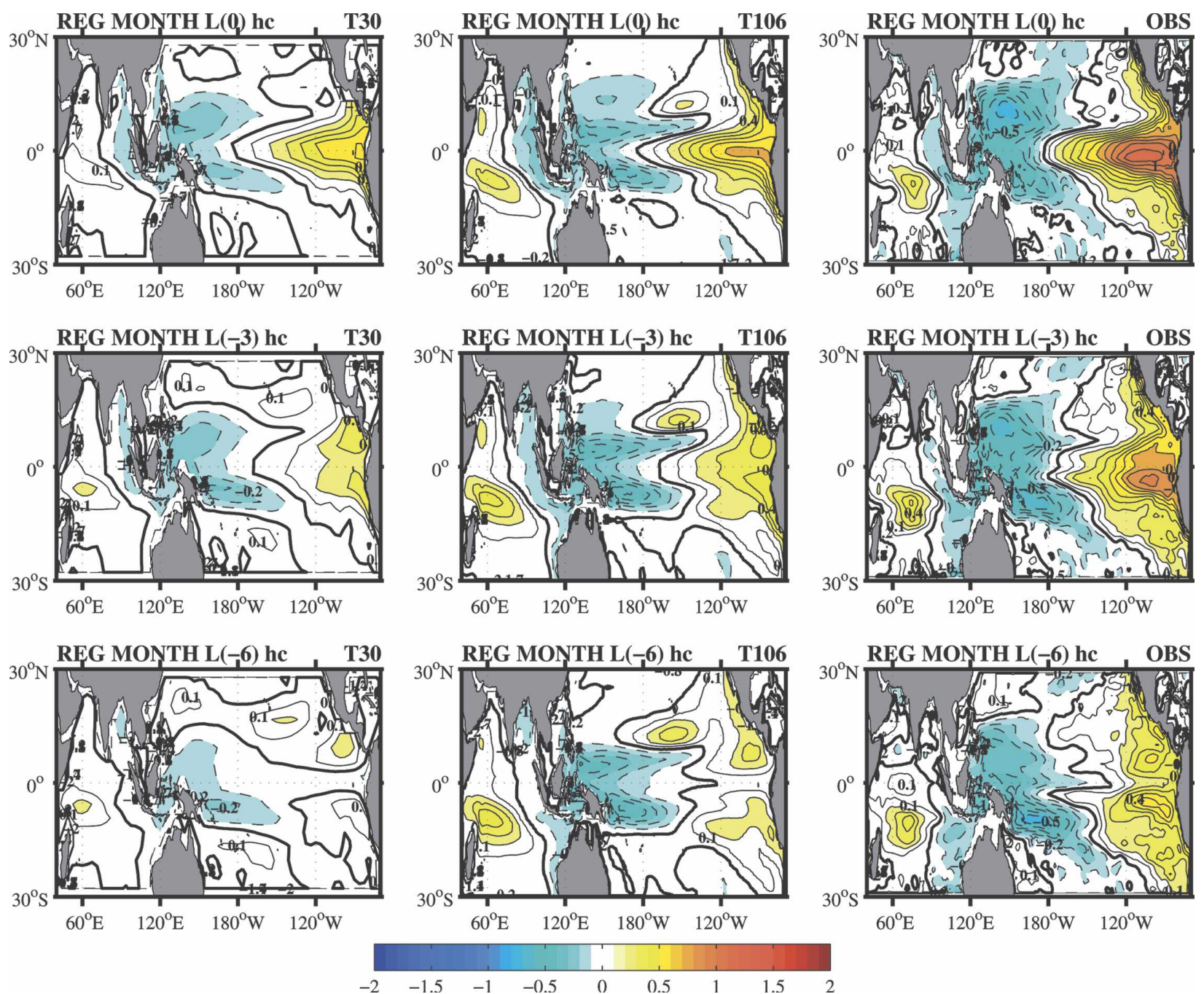

FIG. 13. As in Fig. 12 but for lagged regression to the Niño-3 index for the heat content; (top) zero-lag regression, (middle) 3-month regression, and (bottom) 6-month regression. The Niño-3 index is leading the heat content field and so the panels represent the situation after the Niño-3 variations.

speed is realistic in both models and the amplitude is rather similar, though the models seem to generate larger-scale waves.

The situation is somewhat different in the northernmost band, $15^{\circ}-20^{\circ} \mathrm{N}$, where the reanalysis indicates waves triggered by coastal activity next to the American continental coast. The models react differently. The T30 model generates waves far into the central-eastern Pacific, to the west of the position indicated by the reanalysis, whereas the T106 model places the Rossby waves in the correct position but with weaker amplitude.

\section{Other processes affected by the atmospheric resolution}

The improved atmospheric resolution also has the effect to allow a better representation of several other processes. They may not be directly linked to the main atmosphere-ocean ENSO dynamics, but they collectively contribute to shape the basic state of the Pacific. We will discuss two cases to show this point.

\section{a. Coastal forcing in the Mexican region}

This region has been identified as a potential area for strong interaction between the orography and the coastal ocean by McCreary et al. (1989). Wind bursts are shaped by the Mexican orography in thin fast jets that force the coastal ocean. The process is investigated in Fig. 16, which represents the surface wind stress and the curl in the area. The jets are produced by the T106 model, are absent in the T30, and have been underestimated by the reanalysis (see bottom panel of Fig. 16), presumably for lack of resolution. Recently, high- 

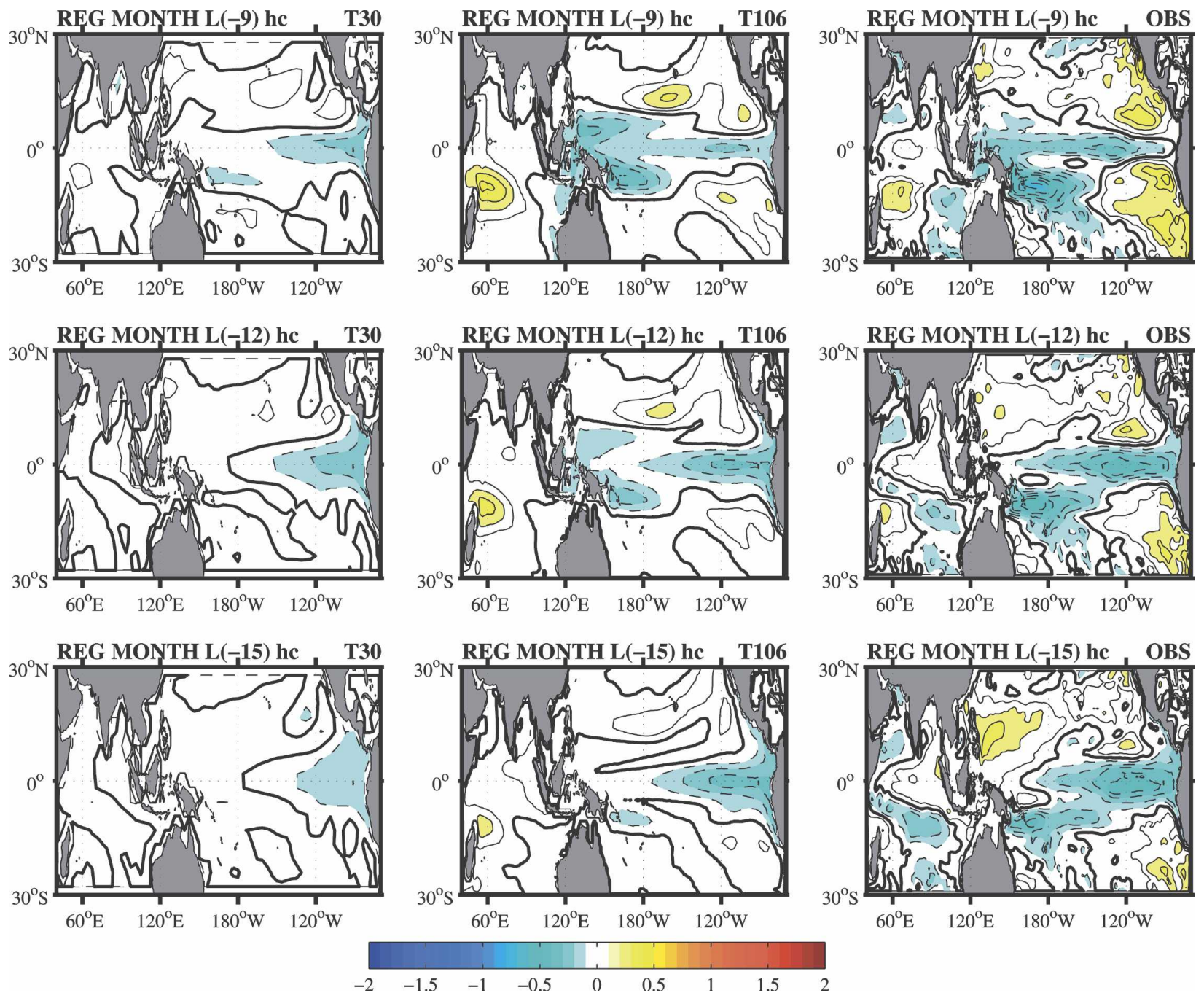

FIG. 14. As in Fig. 13 but for (top) 9-, (middle) 12-, and (bottom) 15-month regression. The Niño-3 index is leading the HC field and so the panels represent the situation after the Niño-3 variations.

resolution surface stress products (Chelton et al. 2004) from satellite observations have identified structures very similar to those shown by the T106 model. The average JFM wind stress and curl data for the period 2000-2005 from the Quick Scatterometer (QuikSCAT)/ SeaWinds scatterometer (QSCAT) observations (Fig. 17) show that the high-resolution model is reproducing correctly these features in this region. The better representation of the wind field in the near-coastal area of the east Pacific is a contributing factor to the improvement in the basic state in the region.

\section{b. Tropical instability waves and wind intensity}

Several studies using satellite data (Liu et al. 2000; Chelton et al. 2001) show a strong coupling between wind and SST anomalies associated with the TIW sig- nal. Wind is accelerated over warm anomalies and decelerated over cold ones producing centers of convergence and divergence in correspondence of the maximum SST gradients. This positive SST-wind speed correlation represents a clear SST influence on the atmosphere and is consistent with a vertical wind adjustment of the atmosphere in the boundary layer: increased SST reduces the static stability of the nearsurface atmosphere, intensifies turbulent mixing that brings down fast moving air from above, and accelerates the surface wind. Wind speed reduction due to the same mechanism is observed over the cold SST anomalies. It has been suggested (Hashizume et al. 2001) that SST-induced sea level pressure changes also contribute to wind fluctuations. The first mechanism seems to be active in the far eastern Pacific, while the second one is 

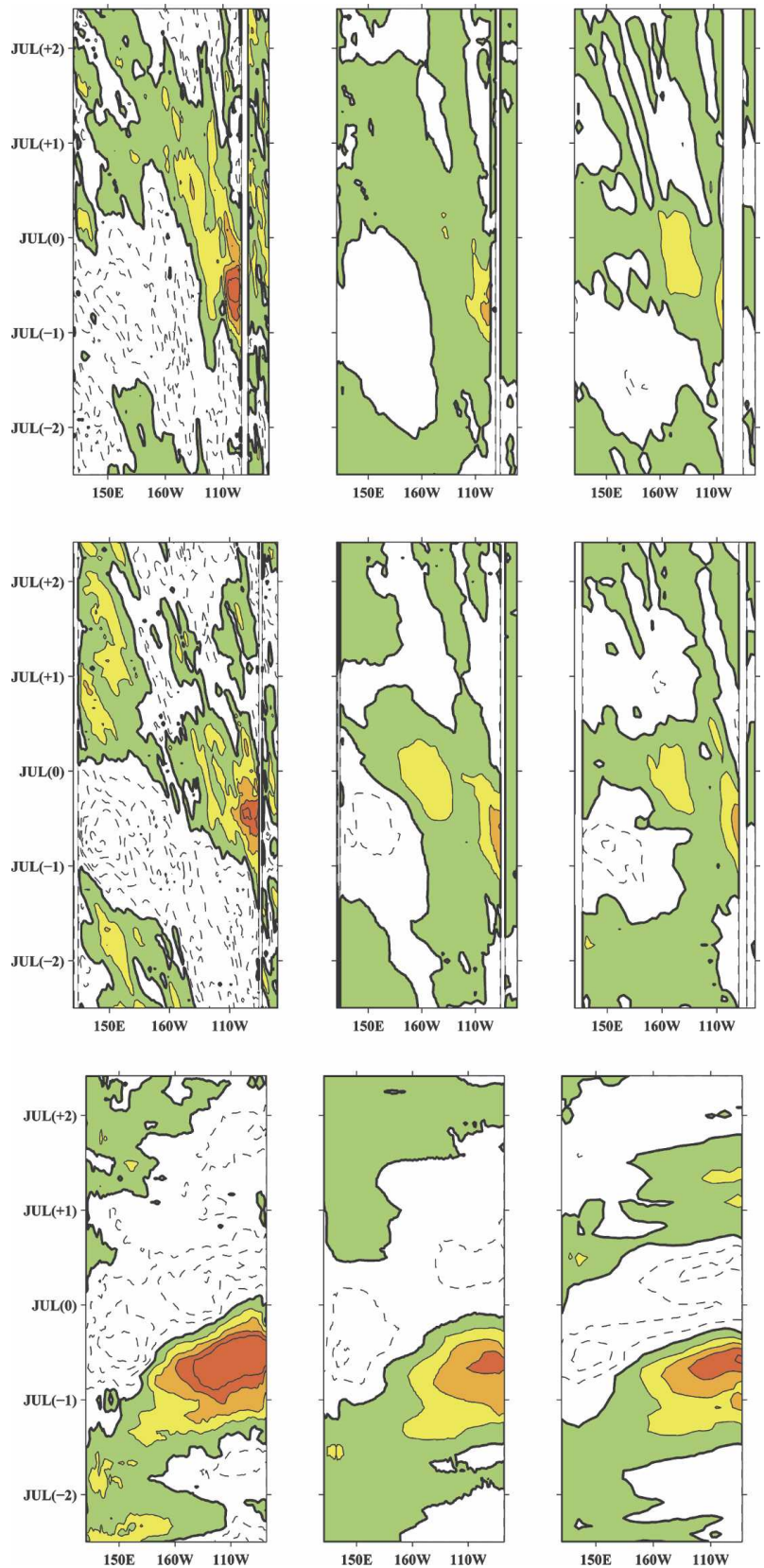

FIG. 15. Heat content time-longitude plots from (left) the ocean data assimilation analysis and the models (middle) T106 and (right) T30, based on composites for the Niño events; (top) averaged in the latitude band $15^{\circ}-20^{\circ} \mathrm{N}$, (middle) for the latitude band $10^{\circ}-15^{\circ} \mathrm{N}$; and (bottom) for the latitude band $5^{\circ} \mathrm{S}-5^{\circ} \mathrm{N}$. The time direction is bottom up and the data have been averaged in the latitude bands indicated above the plots. The contour interval is $0.4^{\circ}$.

in the central Pacific. A positive SST-wind correlation has been observed also south of the equator (Hashizume et al. 2001), where the wind variability induced by SST anomalies is even larger than that north of the equator.
The ocean model produces readily TIW in both models at T30 and at T106; however, Fig. 18 shows that the atmosphere reacts to the TIW only at T106. The lowresolution atmospheric model is effectively decoupled from the ocean at this spatial scale and there is no signature of the TIW in the atmosphere. The T106 shows the typical signature for the TIW as it has been shown by Chelton 2005 in an area close to the equator, between $5^{\circ} \mathrm{N}$ and $5^{\circ} \mathrm{S}$.

As indicated by the divergence pattern, the surface stress acquires a spatial modulation that follows the propagation of the TIW. The modulation can be a factor inducing a feedback from the atmosphere to the ocean, which could possibly affect the mean state of the region.

\section{The coupled manifold at different resolutions}

In the preceding sections we have described the differences in the simulation in terms of the time-mean response, the variability, and some of the processes where the differences in resolution seem to play a role. Processes in the equatorial Pacific are dominated by the vast atmosphere-ocean interaction that takes place there, so it would be important to be able to assess if changes in resolution lead to a qualitative different behavior of the coupling processes. The analysis of the coupled processes is rather straightforward in simpler models, but more difficult in a fully coupled GCM or the observations. This method will allow us to estimate the regional extent and the intensity of the coupling between atmosphere and ocean and how this is affected by changes in the atmospheric resolution.

However, the concept of coupled manifold (Navarra and Tribbia 2005) can be used to identify the oceanatmosphere interactions in the models and in the observations. The coupled manifold can be thought of as the portion of the atmospheric and oceanic variability that is coupled together. It can be represented mathematically as a subspace of each field used in the analysis. The subspaces can be estimated from the model or observed data, assuming that a linear operator exists between two fields.

For instance if we consider the SST data as a matrix, $\mathbf{S}$, and similarly some atmospheric field, $\mathbf{Z}$, we can look for a linear operator $\mathbf{A}$ that satisfies

$$
\min \|\mathbf{Z}-\mathbf{A S}\|^{2}
$$

The best estimate of $\mathbf{A}$ can be found formally as

$$
\mathbf{A}=\mathbf{Z S}^{\prime}\left(\mathbf{S S}^{\prime}\right)^{-1}
$$




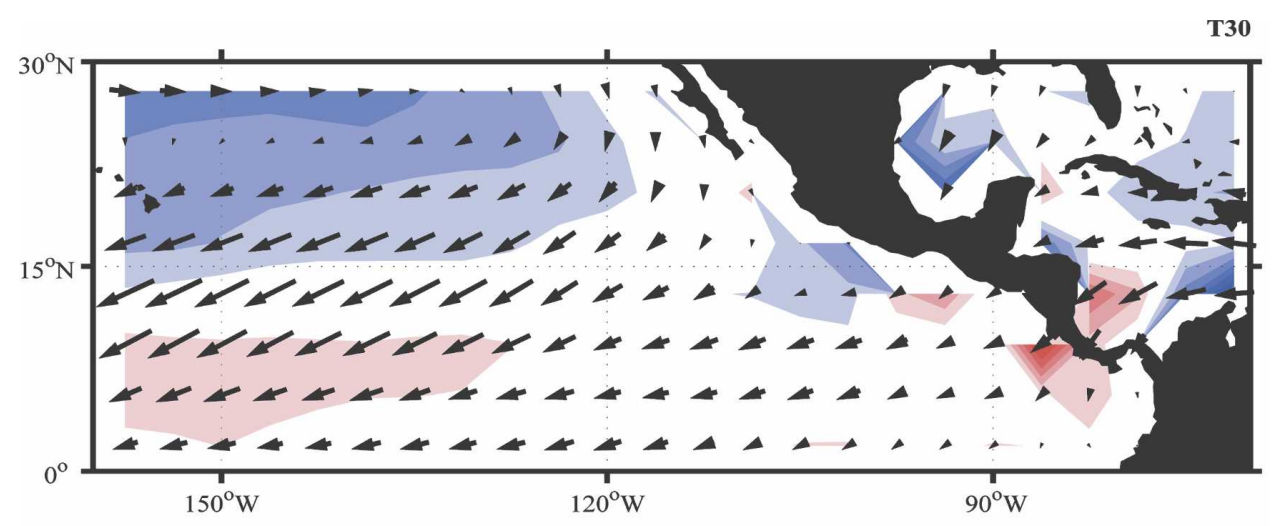

T106
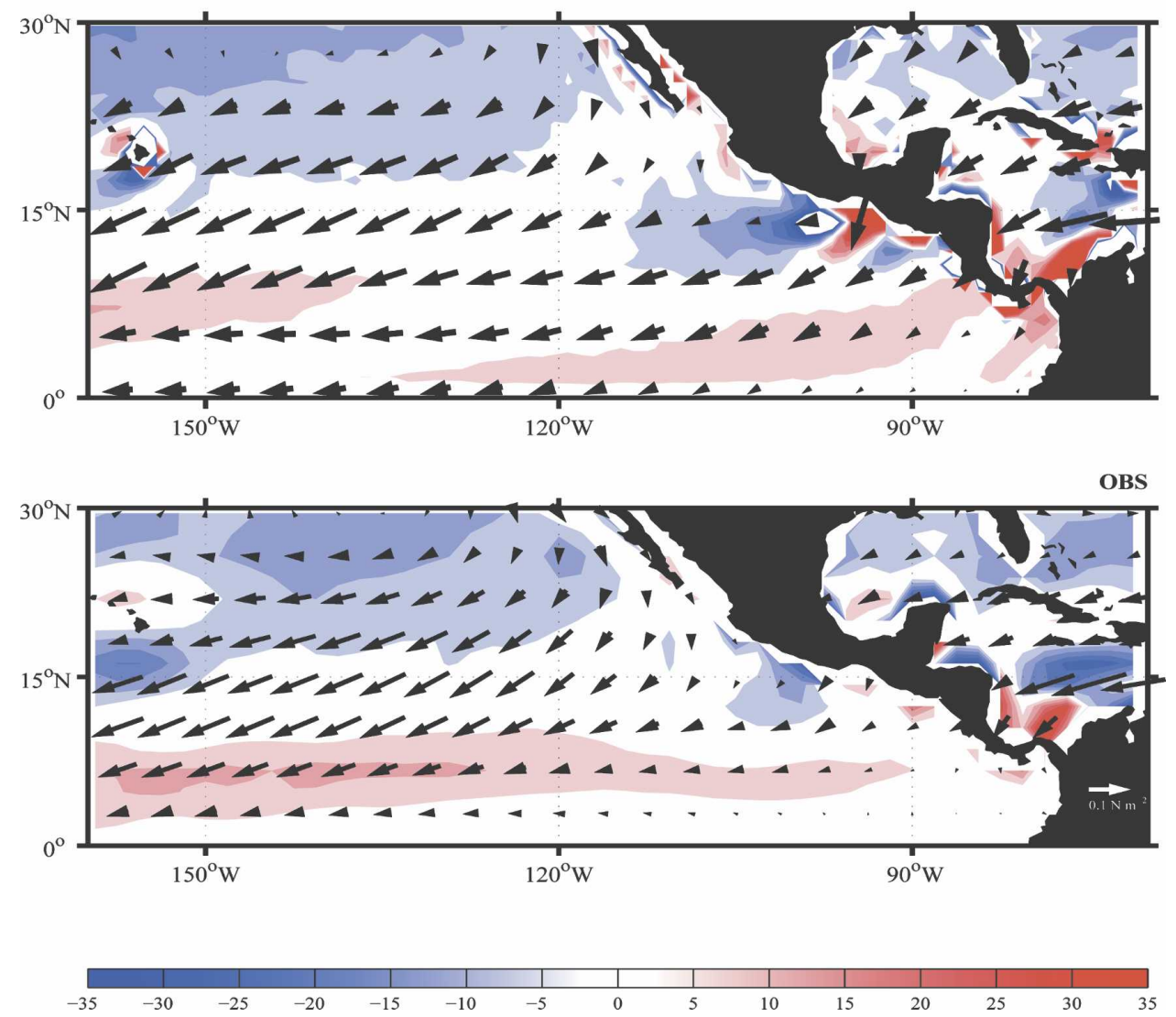

FIG. 16. Surface wind stress and wind stress curl for winter (JFM) in the Mexican region: (top) T30, (middle) T106, and (bottom) observations. Positive values are shown in red and negative in blue; the contours are $5.0 \times 10^{8} \mathrm{~N} \mathrm{~m}^{-3}$.

where the primes denote a matrix transpose operation and a pseudoinverse is used if the $\mathbf{S S}^{\prime}$ matrix is not full rank. The method can be applied regardless of the size of the area involved or the number of grid points used. The data can be scaled by the square root of the their respective covariance $\tilde{\mathbf{S}}=\left(\mathbf{S S}^{\prime}\right)^{-1 / 2}$, so that the scaled data have unit covariance $\tilde{\mathbf{S}} \tilde{\mathbf{S}}^{\prime}=1$. The detailed procedure is described in Navarra and Tribbia 2005.
We have added another element to the original concept of coupled manifold in Navarra and Tribbia 2005 by introducing a statistical significance test for the estimation of $\mathbf{A}$. Under the scaling described previously the estimate of the coupling operator $\mathbf{A}$ is simply $\tilde{\mathbf{Z}} \tilde{\mathbf{S}}^{\prime}$ and it can be shown that each element of $\mathbf{A}$ is a correlation coefficient. Each element of $\mathbf{A}$ can then be tested for statistical significance against the null hypothesis 


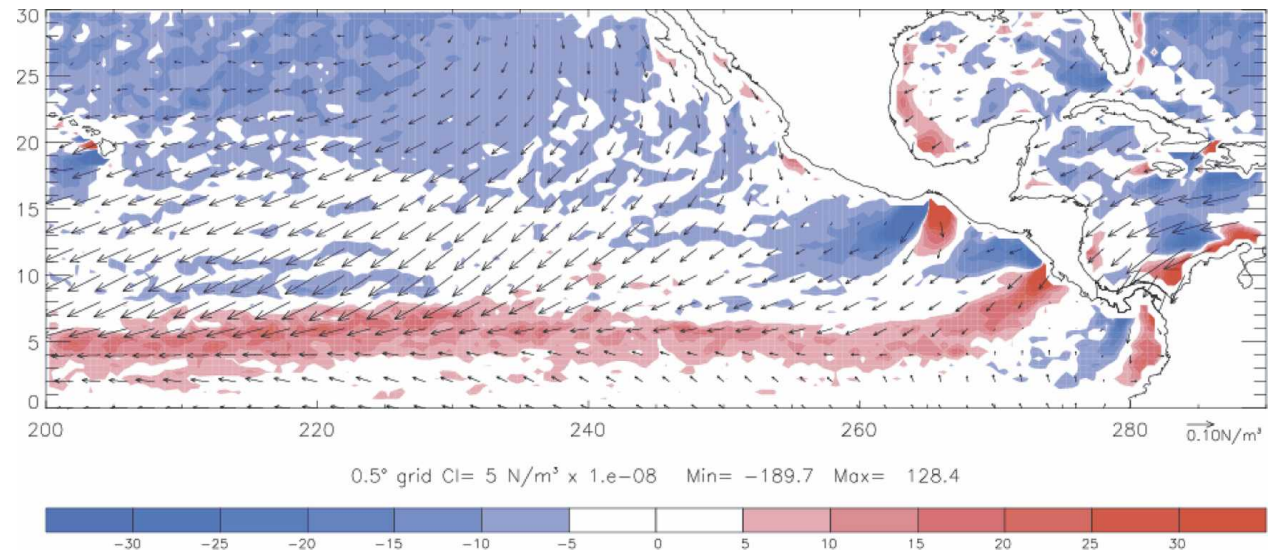

FIG. 17. Surface wind stress and wind stress curl for winter (JFM) for the period 2000-05 in the Mexican region from the QuikSCAT surface data. Positive values are shown in red and negative in blue; the contours are $5.0 \times 10^{-8} \mathrm{~N} \mathrm{~m}^{-3}$ (R. Milliff 2006, personal communication).
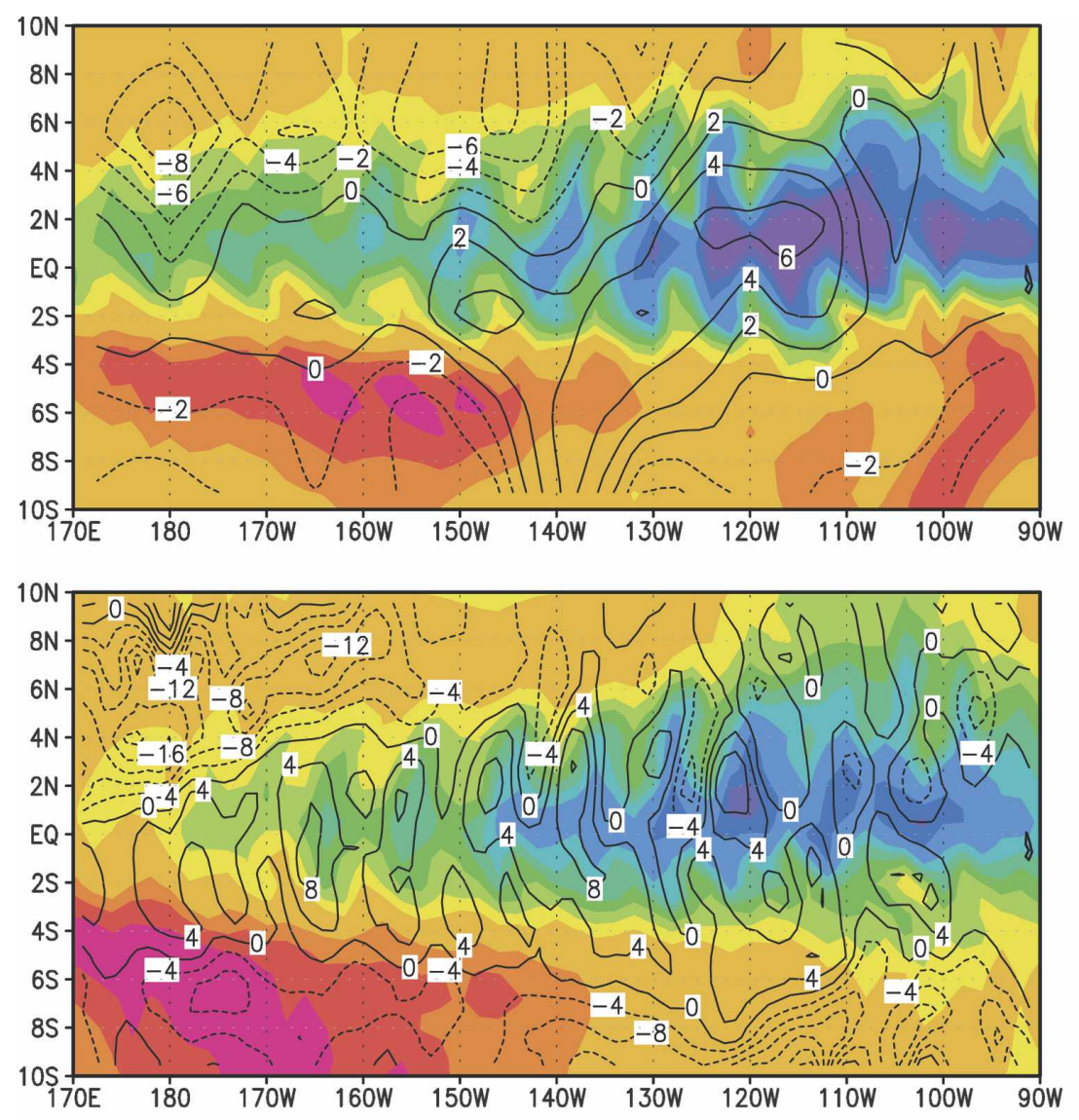

\section{$\begin{array}{llllllllllll}22.5 & 23 & 23.5 & 24.5 & 25 & 25.5 & 26 & 26.5 & 27 & 28 & 28.5 & 29\end{array}$}

FIG. 18. Snapshot of the SST (shaded) and the divergence of the surface stress (contours) for pentads: (top) T30 and (bottom) T106. The contour interval for SST is $0.5^{\circ} \mathrm{C}$ and it is arbitrary for divergence. 

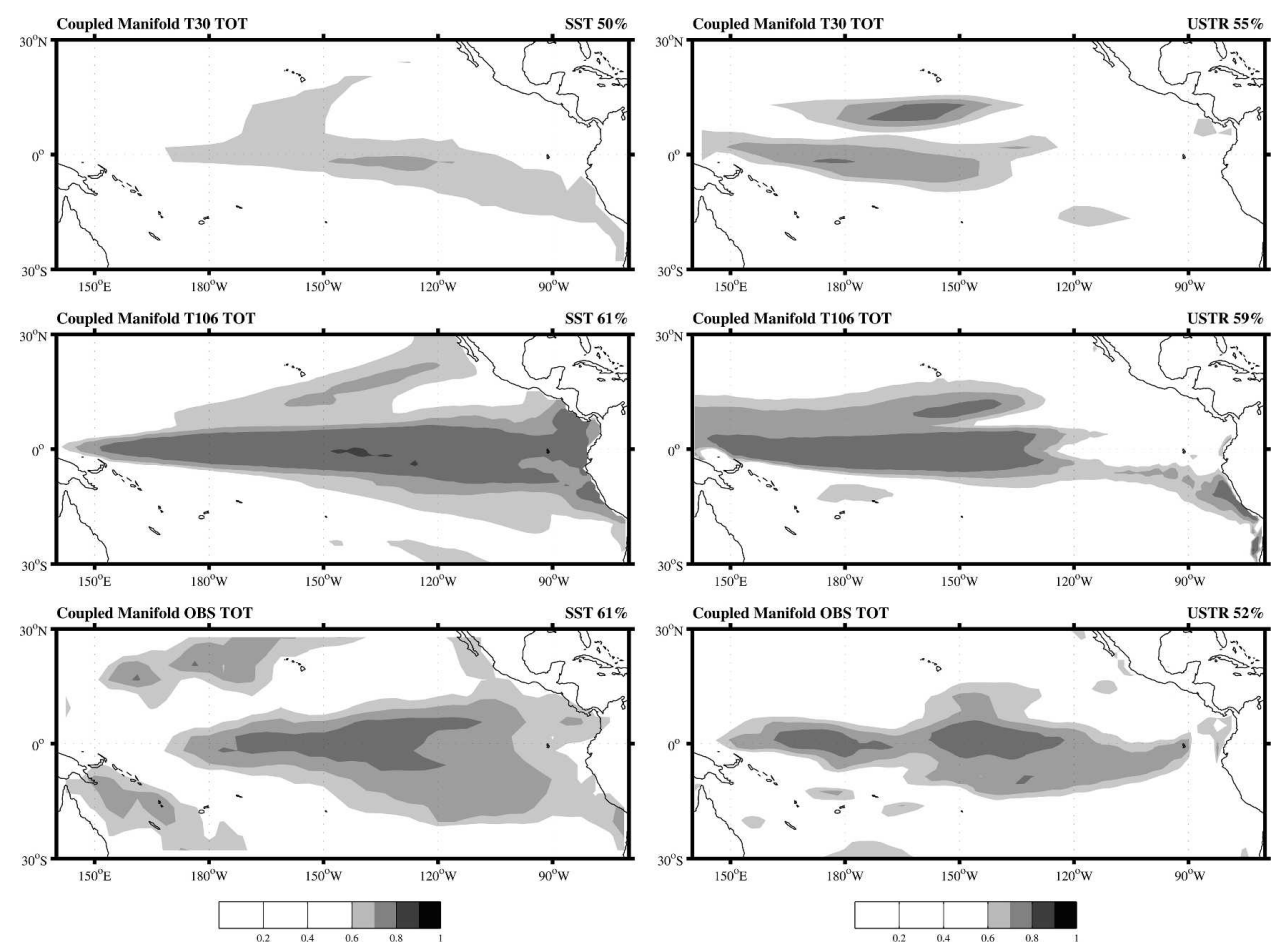

FIG. 19. (left) Fraction of the SST variance explained by the $\mathbf{U}$ stress and (right) fraction of the $\mathbf{U}$-stress variance explained by the SST. (top to bottom) T30, T106, and observations; annual mean values are used. The observations used were the HadISST dataset for the SST and the NCEP reanalysis for the zonal $\mathbf{U}$ stress.

that the correlation is zero. In the following, only the coefficients that passed a $5 \%$ significance criterion have been retained in the construction of the coupling operator $\mathbf{A}$.

\section{a. SST and wind stress}

This method can separate the time series of each field in the part that is cross correlated with the other. The resulting time series can then be used for further processing. In the following we have considered the ratio of variance of the cross-correlated portion with respect to the total to yield an estimate of the strength of the coupling relation. We have considered instantaneous relation, but the generalization to the lagged case is immediate.

The analysis can be applied to the Pacific tropical region using the annual mean SST as the $\mathbf{S}$ field and the annual mean zonal $\mathbf{U}$ stress as the $\mathbf{Z}$ field. Annual means are not enough to capture the complex relation of ENSO with the annual cycle, but we are using them here to provide a first comparison of the behavior of the different models. The left column of Fig. 19 shows the total amount of SST variance that can be explained by the zonal $\mathbf{U}$ stress. In the observations, $64 \%$ of the variance of the SST over the entire area considered can be attributed to $\mathbf{U}$ stress variations. There is a wide region in the central Pacific where the SST variance explained by wind is locally larger. In the eastern $\mathrm{Pa}$ cific, the explained variance is smaller and tends to hug the continental coasts north and south of the equator.

The low-resolution model (top panel) gives a very different picture. The areas of explained variance are much smaller, narrow, and confined to the equatorial region. The averaged explained variance over the entire domain under consideration is $52 \%$. The highresolution model (middle panel) is still not completely satisfactory, but it represents an improvement over the low-resolution case. The pattern of explained variance is closer to the observations and larger values of variance are locally reached. The high-resolution model over all explained variance is $64 \%$. Though the perfect score is probably casual, the result indicates that highresolution models get closer to the observed values using this particular metric. Further development of models will have to reproduce the feature.

The coupled manifold can also be used to explain the U stress in terms of the SST variations (Fig. 19, right column). Also in this case, the high-resolution model 

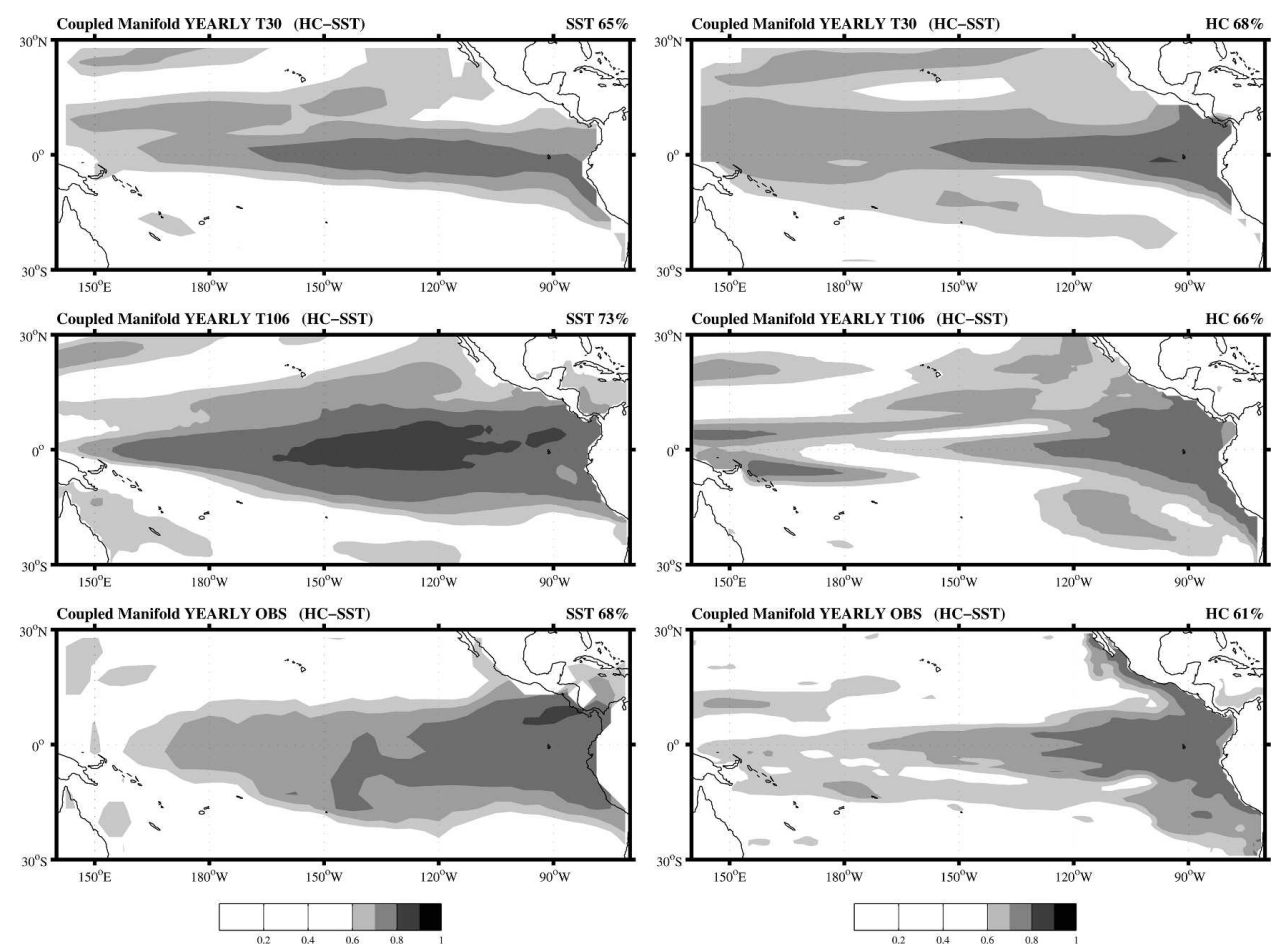

FIG. 20. (left) Fraction of the SST variance explained by the heat content and (right) fraction of the heat content variance explained by the SST. (top to bottom) T30, T106, and observations; annual mean values are used. The observations used were the HadISST dataset for the SST and the ocean reanalysis for the heat content.

seems to be closer to the observations than the lowresolution model. It is tempting to use the definition of the coupled manifold to conclude that the areas where the SST explains a large portion of the stress variance and also the stress explains a large portion of the SST variance are indicative of strong coupling between the two fields. Using this interpretation, we can characterize one problem of the low-resolution model as an insufficient coupling of the atmosphere with the ocean, whereas the high-resolution model is capable to describe a more intense coupling.

A similar analysis can be done on the $\mathbf{V}$ stress (not shown). The inspection of these figures seems to indicate that the variation of the surface stress is positioned at the margin of the SST distribution (see also Fig. 3), where the gradients are stronger. The models tend to overestimate this mechanism. In the T30 model the reaction of the wind to SST is really weak and it can barely be seen; in the T106 model it is probably too strong, but it tends to position in a more realistic way.

\section{b. SST and heat content}

The response of the surface stress to the SST is somewhat weak, as in the T30, or close to the surface gradi- ents of SST, rather than to the SST itself. A consequence of the delayed oscillator theory is that the SST is in balance with the thermocline (Kirtman 1997). It is therefore interesting to consider the coupled manifold of the SST with a parameter representing the thermocline. We will use the heat content, defined previously as an indicator of thermocline variability. The SST enters the calculation of the heat content, but the weight of the SST itself in the vertical integral of the heat content is minor, representing a very shallow layer at the top $(5 \mathrm{~m})$.

The coupled manifold for the SST and the heat content are shown in Fig. 20. The panels show that the fraction of the SST variability explained by the HC is slightly larger than that explained by the surface stress, $68 \%$. The distribution is consistent with the idea that the delayed oscillator mechanism is active in both models, but in the low-resolution experiment it is confined to a narrow region around the equator, whereas in the high-resolution model it extends to a wider belt of latitudes. This result seems to indicate that the delayed oscillator can take different forms, depending on the latitudinal extent of the channel where the waves are generated and coupled to the atmospheric field. 
It is also interesting to note how the amount of SST variance explained by the $\mathrm{U}$ stress and the $\mathrm{HC}$ is distributed in different areas. The SST variations seem to be strongly linked to the $\mathrm{HC}$ in the east Pacific, developing into a wide pattern into the central Pacific. On the other hand, the SST variations are strongly explained by $\mathbf{U}$-stress variations in the central Pacific. The models tend to misrepresent this behavior; the lowresolution model tends to have a really small fraction of the SST variance explained by the stress, whereas the SST variance is explained mostly by the $\mathrm{HC}$ variations. The high-resolution model realizes a better mix of the two mechanisms, and although it is still far from being satisfactory, it is closer to the observations.

\section{Discussion}

One of the most interesting results of this paper is the indication that the higher-resolution model is coupled to the atmosphere in wider region than the lowresolution model. The effect may appear counterintuitive since the low-resolution model has a natural tendency to spread out the atmospheric information over a wider oceanic area. However, the spreading may actually be a negative factor in the simulation of how the ocean and atmosphere interact. A low-resolution atmospheric model will spread the same information over a large number of ocean grid boxes, resulting in an unrealistic uniformity of forcing over the ocean. The examples of the tropical instability waves show how the low-resolution atmospheric model is missing the interaction with the ocean at the smaller scales and therefore is not able to represent the consequent TIWinduced feedback to the ocean. The high resolution is exerting its impacts through small-scales effect like this, resulting in a better variability of wind forcing in the east Pacific. Processes like these contribute to create a different basic state in the T106 from the T30. The change of basic state is visible in the mean SST (Fig. 3) and in the mean surface stress (Figs. 4 and 5). The winter wind stress in the T106 is more realistic than the $\mathrm{T} 30$ at the equator and it has a better geographical extension, stopping short of the date line rather than extending right to it as in the T30 case. The summer wind stress is also weaker at the equator and therefore closer to the observed values. Probably, also as a consequence of the weaker winds, the SST in the western Pacific is warmer and the $29^{\circ}$ area is larger in the T106 and extends over a wider latitudinal extent. The cold tongue, however, is still extending too much west.

The Pacific can sustain a large variety of interannual ocean and coupled modes (Jin 2001; Fedorov and Philander 2000) and the basic state can select to emphasize one or the other (Dewitte et al. 2007). Weaker winds at the equator and a larger meridional scale have also been connected with longer ENSO time scales (Kirtman 1997; Capotondi et al. 2006), as the basic state simulated by the T106 coupled model shows a more realistic meridional profile of the zonal wind stresses that is favorable to the slower modes. The change in the basic state is affecting the mixing of the different modes of interannual variability as they were identified by Fedorov and Philander (2000). The SST mode is limited to the equator and does not involve much off-equator variability of the thermocline, whereas the thermocline mode connected to the delayed oscillator shows offequator variability. In practice the variability includes both modes and so the changes in the basic state modify the relative mix of the two. However, inspection of the heat content standard deviation (not shown) also shows that there is more activity off the equator in the T106, rather than in the T30. The more prominent role of the delayed oscillator mode can also be seen in Figs. 13 and 14, which show how the T106 stays coupled longer than the T30, and in the coupled manifold (Figs. 19 and 20) that also indicates coupling over a wider area. The difference between T106 and T30 can then be understood as a more prominent role played by the delayed oscillator mode in the T106 due to the differences in basic state between the two simulations.

\section{Conclusions}

This paper has shown that using a high horizontal resolution atmospheric component in a coupled model is beneficial regarding the space-time characteristics of the tropical variability. The improvement is mostly visible in the Pacific, but certain aspects of the surface atmospheric circulation in the Indian sector that is crucial for the simulation of the summer Indian monsoon are also improved. The comparison between the lowand high-resolution models shows that in the highresolution model the delayed oscillator is at work in a more realistic set of parameters. The interaction between ocean and atmosphere is realized in a wider latitudinal region and not confined in a narrow strip along the equator. The extension of more off-equatorial regions into the coupling allows the triggering of slower off-equatorial waves that allow slower time scales and shift the dominant Niño-3 variability toward longer time periods.

The introduction of high horizontal resolution has other effects related to the introduction of smaller-scale mechanisms. The coastal upwelling along the South American coast is improved, reducing the systematic error in the mean SST in the east Pacific. Regions of 
strong curl along the Mexican Pacific coast are visible in high-resolution satellite observations and are present in the T106, but totally absent in the T30 and barely hinted at in the reanalysis. They are probably linked to better resolved orographic features. Tropical instability waves become coupled to the atmosphere, showing a clear signature pattern in the divergence field, as has been discussed by Chelton (2005). The ocean component is producing tropical instability waves in both models, but the atmosphere becomes sensitive to them only in the high-resolution case. There is also some ground to argue that the reanalysis is showing its limitation due to relatively low resolution used, and it is probably time to produce a high-resolution atmospheric reanalysis datasets.

The coupled manifold approach allows the identification of the mechanisms of interannual variability in the models and in the observations. Delayed oscillatorlike mechanisms are the cause of the tropical Pacific interannual variability in the models, but in the low resolution model it is confined to a narrow region close to the equator, yielding a faster period for the oscillation. The results suggest that this is probably due to the faster propagation of the waves in this area and to the weak coupling between $\mathbf{U}$ stress and SST. In the highresolution model, the delayed oscillator involves a wider latitudinal extent and the $\mathbf{U}$ stress is better coupled to the SST with a mix of mechanisms that is probably closer to reality. It can also be speculated that the involvement of slower waves caused by the wider latitudinal extent of the variations in the highresolution model might lead to the spectral shift of the peak of the variability toward longer time scales.

The increase of horizontal resolution therefore has impacts on a variety of phenomena, but it is far from being a "magic bullet" that fixes all the deficiencies of the models. In particular, the presence of a double ITCZ does not seem to be affected by resolution and it continues to afflict the high-resolution simulation. Also, in the Indian Ocean the increase in resolution somewhat negatively affects the variability in the east Indian Ocean. The excessive penetration of the cold tongue and interannual variability too much in the west is also not affected by the change in resolution. The indication, however, is that improvements of the model can have a better return if sufficient resolution is used.

Acknowledgments. This research was partially supported by the Italy-USA Cooperation Program of the Italian Ministry of Environment and by the EU projects ENSEMBLES and DYNAMITE. It is a pleasure to acknowledge Dr. Ralph Milliff of CORA, Boulder, for kindly providing the QuikSCAT data and figure.

\section{REFERENCES}

Battisti, D. S., 1988: Dynamics and thermodynamics of a warming event in a coupled tropical atmosphere-ocean model. J. Atmos. Sci., 45, 2889-2919.

Bengtsson, L., M. Botzet, and M. Esch, 1995: Hurricane-type vortices in a general circulation model. Tellus, 47A, 175-196.

Boville, B., 1991: Sensitivity of simulated climate to model resolution. J. Climate, 4, 469-485.

Boyle, J., 1993: Sensitivity of dynamical quantities to horizontal resolution for a climate simulation using the ECMWF (cycle 33) model. J. Climate, 6, 796-815.

Brankovic, C., and D. Gregory, 2001: Impact of horizontal resolution on seasonal integrations. Climate Dyn., 18, 123-143.

Capotondi, A., A. Wittenberg, and S. Masina, 2006: Spatial and temporal structure of tropical Pacific interannual variability in 20th century coupled simulations. Ocean Modell., 15, 274298.

Chelton, D. B., 2005: The impact of SST specification on ECMWF surface wind stress fields in the eastern tropical Pacific. $J$. Climate, 18, 530-550.

__ and Coauthors, 2001: Observations of coupling between surface wind stress and sea surface temperature in the eastern tropical Pacific. J. Climate, 14, 1479-1498.

—, M. Schlax, M. H. Freilich, and R. Milliff, 2004: Satellite measurements reveal persistent small-scale features in ocean winds. Science, 303, 978-983.

Dewitte, B., C. Cibot, C. Périgaud, S.-I. An, and L. Terray, 2007: Interaction between near-annual and ENSO modes in a CGCM simulation: Role of the equatorial background mean state. J. Climate, 20, 1035-1052.

Duffy, P. B., B. Govindasamy, J. P. Iorio, J. Milovich, K. R. Sperber, K. E. Taylor, M. F. Wehner, and S. L. Thompson, 2003: High-resolution simulations of global climate, part 1: Present climate. Climate Dyn., 21, 371-390.

Fedorov, A. V., and S. G. Philander, 2000: Is El Niño changing? Science, 288, 1997-2002.

Gualdi, S., A. Navarra, and H. von Storch, 1997: Tropical intraseasonal oscillation appearing in operational analyses and in a family of general circulation models. J. Atmos. Sci., 54, 11851202.

— , E. Guilyardi, P. Delecluse, S. Masina, and A. Navarra, 2003a: The role of the Indian Ocean in a coupled model. Climate Dyn., 20, 567-582.

— A. Navarra, E. Guilyardi, and P. Delecluse, 2003b: Assessment of the tropical Indo-Pacific climate in the SINTEX CGCM. Ann. Geophys., 46, 1-5.

- A. Alessandri, and A. Navarra, 2005: Impact of atmospheric horizontal resolution on El Niño Southern Oscillation forecasts. Tellus, 57A, 357-374.

Guilyardi, E., P. Delecluse, S. Gualdi, and A. Navarra, 2003: Mechanism for ENSO phase change in a coupled GCM. $J$. Climate, 16, 1141-1158.

—_, and Coauthors, 2004: Representing El Niño in coupled ocean-atmosphere GCMs: The dominant role of the atmospheric component. J. Climate, 17, 4623-4629.

Hashizume, H., S.-P. Xie, W. T. Liu, and K. Takeuchi, 2001: Local and remote atmospheric response to tropical instability waves: A global view from space. J. Geophys. Res., 106, $10173-10186$.

Jin, F.-F., 2001: Low-frequency modes of tropical ocean dynamics. J. Climate, 14, 3874-3881.

Junge, M. M., R. Blender, K. Fraedrich, V. Gayler, U. Luksch, 
and F. Lunkeit, 2005: A world without Greenland: Impacts on the Northern Hemisphere winter circulation in low- and high-resolution models. Climate Dyn., 24, 297-307.

Kalnay, E., and Coauthors, 1996: The NCEP/NCAR 40-Year Reanalysis Project. Bull. Amer. Meteor. Soc., 77, 437-471.

Kirtman, B., 1997: Oceanic Rossby wave dynamics and the ENSO period in a coupled model. J. Climate, 10, 1690-1704.

Kistler, R., and Coauthors, 2001: The NCEP-NCAR 50-Year Reanalysis: Monthly means CD-ROM and documentation. Bull. Amer. Meteor. Soc., 82, 247-267.

Kobayashi, C., and M. Sugi, 2004: Impact of horizontal resolution on the simulation of the Asian summer monsoon and tropical cyclones in the JMA global model. Climate Dyn., 23, 165-176.

Liu, W. T., X. Xie, P. S. Polito, S.-P. Xie, and H. Hashizume, 2000: Atmospheric manifestation of tropical instability waves observed by QuikSCAT and Tropical Rain Measuring Mission. Geophys. Res. Lett., 27, 2545-2548.

Luo, J.-J., S. Masson, S. Behera, P. Delecluse, S. Gualdi, A. Navarra, and T. Yamagata, 2003: South Pacific origin of the decadal ENSO-like variation as simulated by a coupled GCM. Geophys. Res. Lett., 30, 2250-2258.

,-- _ E. Roeckner, G. Madec, and T. Yamagata, 2005: Reducing climatology bias in an ocean-atmosphere CGCM with improved coupling physics. J. Climate, 18, 2344-2360.

Manabe, S., J. Smagorinsky, J. L. Holloway Jr., and H. M. Stone, 1970: Simulated climatology of a general circulation model with a hydrologic cycle. III: Effects of increased horizontal computational resolution. Mon. Wea. Rev., 98, 175-212.

Masina, S., N. Pinardi, and A. Navarra, 2001: A global ocean temperature and altimeter data assimilation system for studies of climate variability. Climate Dyn., 17, 687-700.

— , P. Di Pietro, and A. Navarra, 2004: Interannual-to-decadal variability of the North Atlantic from an ocean data assimilation system. Climate Dyn., 23, 531-546.

May, W., 2001: The impact of horizontal resolution on the simulation of seasonal climate in the Atlantic/European area for present and future times. Climate Res., 16, 203-223.

_ 2003: The Indian summer monsoon and its sensitivity to the mean SSTs: Simulations with the ECHAM4 AGCM at T106 horizontal resolution. J. Meteor. Soc. Japan, 81, 57-83.

— ECHAM4 AGCM at high resolution: The impact of horizontal resolution on annual mean climate change. Climate Dyn., 17, 407-420.

McCreary, J. P., H. S. Lee, and D. B. Enfield, 1989: The response of the coastal ocean to strong offshore winds: With applica- tion to circulations in the gulfs of Tehuantepec and Papagayo. J. Mar. Res., 47, 81-109.

Navarra, A., 2003: Preface: The SINTEX Project. Ann. Geophys., 46, V-IX.

- and J. Tribbia, 2005: The coupled manifold. J. Atmos. Sci., 62, 310-330.

Pope, V., and R. Stratton, 2002: The processes governing horizontal resolution sensitivity in a climate model. Climate Dyn., 19, 211-236.

Rayner, N. A., D. E. Parker, E. B. Horton, C. K. Folland, L. V. Alexander, D. P. Rowell, E. C. Kent, and A. Kaplan, 2003: Global analyses of SST, sea ice, and night marine air temperature since the late nineteenth century. J. Geophys. Res., 108, 4407, doi:10.1029/2002JD002670.

Roeckner, E., and Coauthors, 1996: The atmospheric general circulation model ECHAM-4: Model description and simulation of present-day climate. Max-Planck-Institut für Meteorologie Rep. 218, 90 pp.

Schopf, P., and M. J. Suarez, 1990: Ocean wave dynamics and the time scale of ENSO. J. Phys. Oceanogr., 20, 629-645.

Sperber, K., S. Hameed, G. L. Potter, and J. S. Boyle, 1994: Simulation of the northern summer monsoon in the ECMWF model: Sensitivity to horizontal resolution. Mon. Wea. Rev., 122, 2461-2481.

Stephenson, D. B., F. Chauvin, and J.-F. Royer, 1998: Simulation of the Asian summer monsoon and its dependence on model horizontal resolution. J. Meteor. Soc. Japan, 76, 237-265.

Stratton, R. A., 1999: A high resolution AMIP integration using the Hadley Centre model HadAM2b. Climate Dyn., 15, 9-28.

Suarez, M. J., and P. S. Schopf, 1988: A delayed action oscillator for ENSO. J. Atmos. Sci., 45, 3283-3287.

Tibaldi, S., T. N. Palmer, C. Brankovic, and U. Cubasch, 1990: Extended-range predictions with ECMWF models: Influence of horizontal resolution on systematic error and forecast skill. Quart. J. Roy. Meteor. Soc., 116, 835-866.

Welch, P., 1967: The use of fast Fourier transform for the estimation of power spectra: A method based on time averaging over short, modified periodograms. IEEE Trans. Audio Electroacoust., 15, 70-73.

Wild, M., P. Calanca, S. C. Scherrer, and A. Ohmura, 2003: Effects of polar ice sheets on global sea level in high-resolution. J. Geophys. Res., 108, 4165, doi:10.1029/2002JD002451.

Williamson, D. L., J. T. Kiehl, and J. J. Hack, 1995: Climate sensitivity of the NCAR Community Climate Model (CCM2) to horizontal resolution. Climate Dyn., 11, 377-397.

Wittenberg, A. T., 2004: Extended wind stress analyses for ENSO. J. Climate, 17, 2526-2540. 